\title{
Anabases
}

ANABASES Traditions et réceptions de l'Antiquité

1 | 2005

Varia

\section{Les Daces, Trajan et les origines du peuple roumain : aspects et étapes d'une controverse européenne}

Michel Pillon

\section{OpenEdition}

Journals

Édition électronique

URL : http://journals.openedition.org/anabases/1303

DOI : 10.4000/anabases.1303

ISSN : 2256-9421

Éditeur

E.R.A.S.M.E.

\section{Édition imprimée}

Date de publication : 1 mars 2005

Pagination : 75-104

ISSN : 1774-4296

Référence électronique

Michel Pillon, «Les Daces, Trajan et les origines du peuple roumain : aspects et étapes d'une controverse européenne ", Anabases [En ligne], 1 | 2005, mis en ligne le 01 septembre 2011, consulté le 20 octobre 2019. URL : http://journals.openedition.org/anabases/1303 ; DOI : 10.4000/anabases. 1303 
Anabases 1 (2005), p. 75-104

\section{Les Daces, Trajan et les origines du peuple roumain: aspects et étapes d'une controverse européenne}

MICHEL PILLON

LE 18 MARS 1791, une supplique en latin, le Supplex Libellus Valachorum, est adressée à l'empereur Joseph II et à la Diète de la principauté de Transylvanie par les représentants de la communauté roumaine transylvaine, prêtres uniates, «intellectuels», Samuel Micu, Gheorghe Sincai, Petru Maior, Ioan Para ${ }^{1}$. Le manifeste «valaque», lu devant la Diète en juin 1791, fut très mal accueilli par les trois nations privilégiées, Saxons, Hongrois, Sicules ${ }^{2}$. Il est vrai que ce document remettait complètement en question les structures politiques et sociales de l'Ancien Régime transylvain. En revendiquant l'égalité des droits politiques en faveur des Roumains de Transylvanie, les signataires du Supplex avançaient deux grands arguments. L'un était très "moderne» et annonçait les mouvements nationalitaires qui allaient bouleverser l'Europe: les «Valaques» faisaient valoir qu'ils étaient démographiquement majoritaires et qu'en particulier ils remplissaient les rangs des régiments transylvains, aussi bien ceux des frontières que des troupes de campagne et de la cavalerie sicule ("...regimina limitanea [...] et fere duae tertiae trium ibidem regiminum campestrium et plus quam una tertia regiminis Siculici equestris ordinis... ") ${ }^{3}$. L'autre, exposé en premier, posait le problème des droits historiques de la communauté roumaine: "Est Natio Valachica omnium Transylvaniae hujus aetatis Nationum longe antiquissima, cum a Romanis ipsam coloniis, per Imperatorem Trajanum saeculo II inchoante in Daciam frequenter copiosissimo veteranorum militum numero ad tutandam Provinciam deductis...» ${ }^{4}$ Les Roumains de Transylvanie affirmaient être les

D. PRODAN, Supplex Libellus Valachorum, Bucarest, Éditions scientifiques et encyclopédiques, éd. en anglais, 1971, p. 43; C. DURANDIN, Histoire des Roumains, Paris, A. Fayard, 1995 , p. 90.

PRODAN, Supplex, p. 45.

PRODAN, Supplex, p. 453.

PRODAN, Supplex, p. 443. 
descendants des colons romains établis par Trajan et ses successeurs, les fils donc de Trajan!

À partir de cette époque, la controverse sur les origines des Roumains et leurs droits historiques sur la Transylvanie débutait et suscitait progressivement une polémique à l'échelle européenne. Deux siècles plus tard, paraissait à Budapest une monumentale Histoire de Transylvanie, d'abord en hongrois, puis assez vite traduite en anglais, allemand et français ${ }^{5}$, très critique à l'égard des thèses roumaines. La réponse ne se fit pas attendre sous la forme d'un ouvrage collectif publié sous les auspices de l'Académie roumaine des Sciences avec un titre sans ambiguïté: Un jeu dangereux: la falsification de l'Histoire ${ }^{6}$. L' "wautochtonéité» roumaine en Transylvanie y était évidemment réaffirmée. Mais, par rapport au manifeste de 1791 qui s'en tenait à l'origine latine des Roumains, les Daces en étaient devenus, dans l'historiographie de la fin du règne de Nicolae Ceausescu, les véritables ancêtres ${ }^{7}$. Une phrase significative du dirigeant communiste roumain est citée dans ce livre: "Depuis la formation de l'État dace centralisé de Burebista au Ir siècle de notre ère, depuis le temps de la société dace florissante de Décébale, et ensuite, durant deux millénaires d'existence, notre peuple dut mener une lutte acharnée pour défendre son identité, son entité comme nation et comme État.» 8

Entre les deux recueils, on peut remarquer des constantes, mais aussi une évolution. D'une part, les antiques origines des Roumains, mais surtout la permanence de leur présence en Transylvanie sont proclamées haut et fort. D'autre part, si les Valaques de 1791 s'affirment être les fils de Trajan, deux cents ans plus tard, à l'époque de Ceausescu, les Daces sont revendiqués comme étant les ancêtres des Roumains. Comme le dit très bien Lucian Boia, à la thèse de l'origine latine succède et s'oppose même celle de l'origine dace des Roumains ${ }^{9}$. Mais, quelle que fût la thèse en vogue dans les milieux intellectuels et patriotiques roumains, «latine» ou «dace», celle-ci a été combattue vigoureusement par les cercles politiques et savants des États limitrophes, Hongrie, Bulgarie tout particulièrement. Mais la controverse ne se limita pas au sud-est de l'Europe. Elle s'étendit à tout le continent européen. Dans ce processus, la recherche d'origine allemande et autrichienne joua un rôle

5 L'ouvrage en trois volumes, publié par les soins de l'Akadémiai Kiadó en 1986, parut dans sa version française abrégée en 1992, sous la direction de Béla Köpeczi. Les historiens hongrois apportèrent leur collaboration à cette œuvre: László Makkai, András Mócsy, István Bóna parmi bien d'autres.

6 Un jeu dangereux: la falsification de l'Histoire. Recueil d'études et d'articles, éd. en français (une édition en anglais a aussi paru), dir. S. Pascu et S. Stefanescu, Bucarest, 1987.

7 M. MUSAT, "Les coordonnées du développement unitaire du peuple roumain sur le territoire de la Dacie ancienne", in Un jeu dangereux, p. 6-7.

8 Un jeu dangereux, citation p. 6.

9 L. BOIA, La Roumanie. Un pays à la frontière de l'Europe, trad. du roumain L. Rossion, Paris, Les Belles Lettres, 2003, p. 43-53. 
fondamental ${ }^{10}$. Les savants allemands et austro-hongrois se partagèrent certes entre «autochtonéistes» et "immigrationnistes». Mais ils firent bénéficier par la même occasion les jeunes recherches des États balkaniques et centre-européens de la science, notamment philologique, des universités germaniques.

Or, dans l'épineux dossier de l'ethnogénèse des Roumains et du milieu géographique où celle-ci avait eu lieu, dès le XVII ${ }^{e}$ siècle les érudits avaient précisément repéré et étudié ce qu'on peut appeler le «trou noir» dans les sources écrites, entre l'époque de l'évacuation par les Romains des Dacies transdanubiennes à la fin du III e siècle et celle de l'apparition de populations valaques, tout d'abord dans les Balkans au $\mathrm{X}^{\mathrm{e}}$ siècle, puis en Transylvanie au XIII siècle. Il y a donc eu chronologiquement une première phase "préparatoire» de la controverse, aux XVII et XVIII siècles, durant laquelle le problème des sources écrites a été posé. Par la suite, quatre étapes jalonnant l'évolution du débat sur les origines roumaines peuvent être distinguées. Elles correspondent tout à fait classiquement aux grandes phases culturelles et politiques européennes: la phase romantique, la phase positiviste, la phase de "l'entre-deux-guerres" (1918-1940) qui, d'une certaine manière, vit l'apogée de la controverse, et la dernière qui fut marquée par la "guerre froide» (1945-1990).

Nous nous proposons de faire préalablement un bref rappel du dossier des sources écrites, tel qu'il se présente au début du XIX ${ }^{\mathrm{e}}$ siècle. Puis, des quatre étapes de la controverse, nous nous intéresserons aux deux qui nous semblent les plus importantes, celle qui fut marquée par les thèses de Roesler au milieu du XIXe siècle, et, en dernier lieu, celle qui fut, dans les années 1930, le moment où la controverse parvint à un remarquable niveau scientifique.

\section{Le dossier des origines roumaines: le «trou noir» des sources écrites}

Les rares sources écrites, essentiellement en latin et en grec (exceptée la vieille Chronique de Nestor rédigée en slavon ${ }^{11}$ ), qui constituent le fondement de nos connaissances sur la question de l'ethnogénèse roumaine et qui ont été durant deux siècles l'objet d'innombrables commentaires, sont parfaitement connues des auteurs du Supplex Libellus Valachorum. Elles sont utilisées pour prouver la thèse de l'origine romaine des Roumains de Transylvanie et l'antériorité de leur établissement dans cette principauté par rapport, naturellement, aux Slaves et surtout aux Hongrois. Il nous semble important de mentionner ces documents écrits qui sont à la base de la controverse. Aux XIXe et $\mathrm{XX}^{\mathrm{e}}$ siècles, le dossier s'épaissira, comme nous le verrons, avec l'intervention de l'archéologie, de la linguistique, de la philologie, de l'épigraphie

10 R. WINDISCH, "Die Herkunft der Rumänien im Lichte der deutschen Forschung”, Vox Romanica 41 (1982), p. 46-72.

11 Chronique de Nestor, éd. TRAUTMANN, 19, 14, Leipzig, 1931. 
et de la numismatique, au point que le débat semblera se livrer entre spécialistes de ces «sciences auxiliaires» de l'Histoire et qu'on aura tendance à négliger l'apport des sources écrites! Quelles sont donc ces sources écrites?

Une première génération est celle issue des historiens latins du $\mathrm{IV}^{\mathrm{e}}$ siècle mentionnant l'évacuation en 270-275 des Dacies transdanubiennes et le transfert (total ou partiel?) de la population «romaine» au sud du Danube sur les ordres de l'empereur Aurélien. Une partie du territoire des deux Mésies et de la Thrace est alors détachée de ces provinces pour former les nouvelles provinces de Dacia Ripensis et Dacia Mediterranea où sont établis les réfugiés romains des Dacies transdanubiennes. Le récit de cette évacuation est d'autant plus succinct que les dits historiens latins sont pour certains des abréviateurs. C'est le cas de Rufius Festus et d'Eutrope ${ }^{12}$. Mais en vérité il n'y a pas plus de précision dans la Vie d'Aurélien de l'Histoire Auguste et chez l'historien des Goths, Jordanès ${ }^{13}$. Ensuite, il n'y plus rien sur le sort des Dacies transdanubiennes, c'est-à-dire sur les trois grands "pays» constituant l'actuelle Roumanie, la Valachie, la Moldavie, la Transylvanie, et cela pour mille ans! C'est le «trou noir» des sources écrites concernant une population de langue latine subsistant dans les trois Tarii roumaines entre les III et XIIIe siècles. Une simple allusion relevée dans le Stratégicon dit du Pseudo-Maurice, manuel militaire byzantin de la fin du VIe siècle, à des "Romains" vivant "dans le pays des Slaves" (la Valachie actuelle) constitue une exception. L'auteur conseille aux officiers des troupes impériales byzantines intervenant au nord du Danube de se méfier des refugi, Romains seulement de nom, car «au fil du temps, ils ont oublié leurs compatriotes et sont

12 Sextus Rufius Festus, Breviarium rerum gestarum populi romani 8, Berlin, M.G.H., A.A.: "Traianus Dacos sub rege Decibalo vicit et Daciam trans Danuvium in solo barbariae provinciam fecit, quae in circuitu decies centena milia passuum habuit, sed sub Gallieno imperatore amissa est et per Aurelianum, translatis exinde Romanis duae Daciae in regionibus Moesiae ac Dardaniae factae sunt.». Eutrope, Breviarium ab Urbe condita VIII, 6, 2, éd. J. HellegOUARC'H, Paris, CUF, 1999: "Post eum (Quintillum), Aurelianus suscepit imperium. Dacia Ripensi oriundus, vir in bello potens, [...] provinciam Daciam quam Traianus ultra Danubium fecerat intermisit, vastato omni Illyrico et Moesia, desperans eam posse retineri, abductosque Romanos ex urbibus et agris Daciae in media Moesia collocavit appellavitque eam Daciam, quae nunc duas Moesias dividit et est dextra Danubio in mare fluenti, cum antea fuerit in laeva.»

13 Flavius Vopiscus, Vita Aureliani (Scriptores Historiae Augustae), éd. E. HOHL, corr. et add. Ch.S AMBERGER et W. SEYFARTH, Leipzig, G. Teubner, 1965, 39, 7-39, 8: "Cum vastatum Illyricum ac Moesiam deperditam (Aurelianus) videret, provinciam Transdanuvinam Daciam a Traiano constitutam sublato exercitu et provincialibus reliquit, desperans eam posse retineri, abductosque ex ea populos in Moesia conlocavit appellavitque suam Daciam, quae nunc duas Moesias dividit.»; Jordanès, Romana 217, éd. Th. MOMMSEN, M.G.H., A.A., Berlin 1882: "Daces autem post haec jam sub imperio suo Traiano, Decebalo eorum rege devicto, in terras ultra Danubium, quae habent mille milia spatia, in provinciam redegit. Sed Gallienus eos dum regnaret amisit Aurelianusque imperator evocatis exinde legionibus in Mysia conlocavit ibique aliquam partem Daciam mediterraneam Daciamque ripensem constituit et Dardania junxit.» 
devenus plus proches des ennemis (slaves); il convient de bien traiter ceux qui ont des sentiments amicaux et de punir ceux qui sont hostiles.» 14

Quatre siècles plus tard, apparaissent dans les sources byzantines, latines et slaves les «Valaques» ${ }^{15}$. Les mentions les plus précises se trouvent chez les Byzantins ${ }^{16}$. Or ces $B \lambda a ́$ Xor que les Byzantins trouvent devant eux lors de leur reconquête de la péninsule balkanique à partir de la deuxième moitié du $\mathrm{X}^{\mathrm{e}}$ siècle n'habitent pas les pays de l'ancienne Dacie transdanubienne. Ils sont disséminés dans l'intérieur des Balkans en communautés plus ou moins nombreuses, mais toujours minoritaires au sein des populations slaves ou hellénophones, de la Macédoine et l'Épire à la rive droite du Danube, donc au sud de ce fleuve! Il était naturel que la question de l'origine des Valaques se posât aux Byzantins. Kécauménos, grand seigneur et officier supérieur de l'Empire au $\mathrm{XI}^{\mathrm{e}}$ siècle ${ }^{17}$, consacre un assez long passage de ses Conseils et Récits aux Valaques de Thessalie et d'Épire. Ceux-ci sont décrits comme un peuple sans foi ni loi, particulièrement instable et dangereux ${ }^{18}$. Ils seraient les descendants des Daces et des Besses soumis par Trajan, puis auraient été chassés de leur patrie danubienne originelle et se seraient établis en Macédoine, Épire et "Hellade» 19. Un siècle plus tard, le chroniqueur Jean Kinnamos signale que, dans l'armée de Jean Vatatzès menant campagne contre les Hongrois, se trouvent des combattants valaques qui «dit-on, sont des colons venus jadis d'Italie» ${ }^{20 .}$ Bien avant le commencement «officiel» de la controverse, les deux thèses sur l'ethnogénèse roumaine, «latiniste» et «dace» étaient donc déjà présentes (et s'opposaient) dans la littérature byzantine aux $\mathrm{XI}^{\mathrm{e}}$ et $\mathrm{XII}^{\mathrm{e}}$ siècles ${ }^{21}$ !

14 Das Strategikon des Maurikios, éd. G.T. DENNIS et E. GAMILLSCHEG, Vienne, 1981,

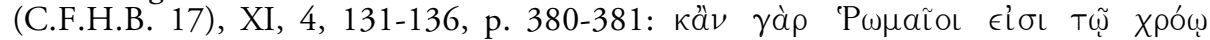

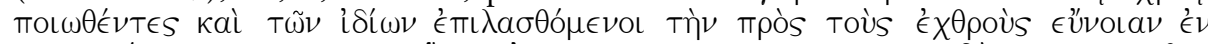

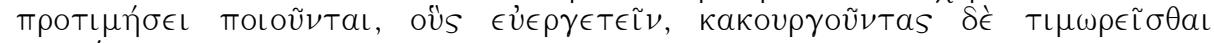
$\pi \rho O \sigma \eta ́ \kappa \in l$.

15 Cf. les différentes variantes et acceptions du terme dans WINDISCH, "Herkunft", p.55-57.

16 Mentions dans: Jean Skylitzès, Synopsis Historiarum, éd. H. THUN, (C.F.H.B. V), Berlin-New York, 1973, 11, 79-80, p. 329; Sigillion de Basile II (1020), in H. GELZER, "Ungedruckte und wenig bekannte Bistümerverzeichnisse der orientalischen Kirche", Byzantinische Zeitschrift 2 (1893), p. 46, 11-12 et 1 (1892), p. 257, III, 23; Kékauménos, Conseils et Récits, éd. B.W ASSILIEWSKY et V.J ERNSTEDT, rééd., Amsterdam, 1965, p. 74 et 96; Anne Comnène, Alexiade, trad. B. LEIB, t. II, Paris, CUF, 1967, VIII, 3, 4, p. 135, 3; Jean Kinnamos, Epitomè VI, 3, éd. A. MEINEKE, C.S.H.B., Bonn, 1836, p. 260; Nicétas Choniatès, Histoire, I.A. VAN DIETEN, BerlinNew York (Corpus Fontium Historiae Byzantinae XI), 1975, t. 2, Index nominum, s.v.

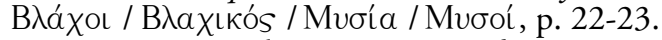

17 P. LEMERLE, Prolégomènes à une édition critique et commentée des "Conseils et Récits" de Kékauménos, Bruxelles, 1960, p. 20-56.

18 Kékauménos, Conseils et récits, Stratégicon $\$ 187$, p. 74, 4-12.

19 Kékauménos, Conseils et récits, Stratégicon $\$ 187$, p. 74, 12-24.

20 Jean Kinnamos, Epitomè.

21 L. BOIA, Roumanie, p. 35-53. 
Les sources byzantines ne sont pas cependant les seules à mentionner les Valaques dans la péninsule balkanique. Il convient d'y ajouter des documents en latin. L'un de ceux-ci est un extrait de la Chronique du Prêtre de Dioclée, écrite probablement au XIIe siècle ${ }^{22}$. Il nous informe que les Bulgares, dirigés par leur Khagan, après avoir envahi la Sylloduxiam Provinciam et la Macédoine, conquirent: "...totam Provinciam Latinorum, qui illo tempore Romani vocabantur, modo vero Moroulachi, hoc est Nigri Latini vocantur" 23. Ce sont les fameux Morlaques des confins de Dalmatie et de Bosnie, renommés pour leurs mœurs farouches ${ }^{24}$. La Chronique s'étant surtout fait l'écho de traditions locales et donc étant chronologiquement très imprécise, les événements en question ont très bien pu avoir lieu entre les VII e et $\mathrm{X}^{\mathrm{e}}$ siècles. Mais là n'est pas le plus important. Nous avons la confirmation que les Valaques étaient connus dans les Balkans pour être les descendants ou héritiers des Romains des régions danubiennes et balkaniques. D'ailleurs eux-mêmes, selon le savant dalmate Lucius, s'appelaient "Romains», Rumeni ${ }^{25}$.

Le deuxième document, bien plus important, a été l'objet des controverses les plus acharnées entre savants roumains et hongrois. Il s'agit de la plus ancienne des chroniques du Royaume de Hongrie. Elle fut écrite par un auteur anonyme, sans doute notaire du Roi de Hongrie Béla III (1172-1196) ${ }^{26}$. D’après cette chronique, les Magyars, avant de franchir les Carpathes en 895, auraient demandé aux chefs ruthènes de Galicie des renseignements sur les populations se trouvant sur le territoire de la «Pannonie». Les Ruthènes répondirent qu'il y avait des Bulgares, des Slaves et des Blachii; ceux-ci, pastores Romanorum, s'y seraient installés après l'effondrement de

22 J. FERLUGA, "Die Chronik des Priesters von Doklea als Quelle für die byzantinische Geschichte", Byzantina 10 (1980), p. 433.

23 Presbyteri Diocleatis regnum Slavorum, in LUCIUS, De Regno Dalmatiae et Croatiae, Amsterdam, 1666, p. 288, 4.

24 Lettre de M. l'abbé Fortis à Mylord comte de Butte sur les mours et usages des Morlaques appelés Monténégrins (1778), cité in J.M. DOMENACH et A. PONTAULT, Yougoslavie, Paris, éd. du Seuil, coll. Petite Planète, 1971, p. 175.

25 LUCIUS, De Regno, p. 284.

26 P. Magistri, qui Anonymus dicitur, Gesta Hungarorum, éd. et comm. E. JAKUBOVICH, compl. D. PAIS, dans Scriptores Rerum Hungaricarum tempore ducum regumque stirpis Arpadianae gestarum, éd. E. SZENTPETERY, t. I, Budapest, 1937, p. 13-117. Sur le notaire anonyme, cf.dans préface de E. JAKUBOVICH, p. 25-30 et dans le t. II des Scriptores Rerum Hungaricarum (Budapest, 1938, p. 631-634), l'étude de L. SZILAGYI, De aetate ac persona P. Magistri, Anonymi Belae regis notarii. 
l'empire d'Attila ${ }^{27}$. Le secrétaire anonyme, un peu plus loin, précise l'origine de l'implantation de ces pastores et le secteur géographique où ils menaient paître leurs bêtes. C'étaient à des Romani principes qu'appartenaient ces troupeaux, et les pâturages étaient ceux de la grande plaine hongroise drainée par le Danube, la Tisza, le Maros, le Vág, le Körös, le Tëmüs ${ }^{28}$. Le passage de la Chronique qui parait le plus favorable aux thèses roumaines est cependant celui qui relate l'expédition du chef magyar Tuhutum en Transylvanie. Là règne un chef valaque, Gelu ou Gelou ${ }^{29}$, appelé $d u x$ Blacorum ${ }^{30}$, qui finit par succomber sous les coups des envahisseurs ${ }^{31}$. Les auteurs du Supplex Libellus Valachorum ne manquèrent pas de rappeler à l'empereur et à la Diète transylvaine cet épisode retranscrit dans la plus vieille chronique hongroise 32 !

Les renseignements fournis sur les Valaques par le notaire du Roi de Hongrie sont corroborés par deux autres documents. L'un provient d'une description géographique de l'Europe orientale écrite probablement par un dominicain français en $1308{ }^{33}$. Celui-ci signale qu’à cette époque vit dans les montagnes, entre Macédoine et Épire, le puissant peuple des Blazi ou Blachi (évidemment des Valaques), autrefois «bergers des Romains» en Hongrie. Mais chassés par les Hongrois, ils émigrèrent en

27 P. Magistri 9, p. 45-46: "Duces vero Ruthenorum [...] rogaverunt Almum ducem (le père d'Arpad), ut dimissa terra Galicie ultra silvam Hovos versus occidentem in terram Pannonie descenderent, quo primo Athile regis terra fuisset, et laudabant eis terram Pannonie ultra modum esse bonam. Dicebant enim, quod ibi confluerent nobilissimi fontes aquarum, Danubius et Tyscia et alii nobilissimi fontes bonis piscibus habundantes, quam terram habitarent Sclavii, Bulgarii et Blachii ac pastores Romanorum. Quia post mortem Athile regis terram Pannonie Romani dicebant pascua esse eo, quod greges eorum in terra Pannonie pascebantur. Et jure terra Pannonie pascua Romanorum esse dicebatur, nam et modo Romani pascuntur de bonis Hungarie."

28 Ibidem 11, p. 48: "...quod terra illa nimis bona esset et ibi confluerent nobilissimi fontes, quorum nomina hec essent, [...] : Danubius, Tyscia, Wag, Morisius, Crisius, Temus et ceteri, que etiam primo fuisset terra Athile regis et mortuo illo preoccupassent Romani principes terram Pannonie usque ad Danubium, ubi collocavissent pastores suos."

29 Ibidem 24, p. 65: "...tunc Tuhutum pater Horca [...], dum cepisset audire ab incolis bonitatem terre Ultrasilvane, ubi Gelou quidam Blacus dominium tenebat, cepit ad hoc anhelare..."

$30 \quad$ Ibidem 26, p. 66.

$31 \quad$ Ibidem 27, p. 67.

32 PRODAN, Supplex, p. 444: "Dum Hungari ad finem saeculi IX sub Duce Tuhutum Transylvanas partes invaserunt Romani earundem incolae, mutato nomine, "Vlahi" appellabantur, testante antiquissimo Hungariae scriptore Anonymo Belae Regis Notario: proprius tunc temporis ipsis praeerat Dux Gelou suprema cum potestate, in pugna tamen quam pro tutanda Patria cum Hungaris inivit infelix, cum in illa dominatum et vitam amiserit."

33 Anonymi Descriptio Europae Orientalis, éd. et comm. O. GORKA, Cracovie, 1916. Sur l'auteur, préface p. IX-XVI. 
masse dans les régions où ils se trouvent encore ${ }^{34}$. À cette notice sur les Valaques du Pinde peut être rattaché ce que dit l'auteur anonyme sur la Hongrie elle-même qui, avant d'être conquise par les Magyars, était la zone de pâturages de pastores Romanorum ${ }^{35}$. Il est bien possible que, les Gesta Hungarorum et la Descriptio Europae Orientalis aient utilisé les mêmes données sur les Valaques ou bien que le dominicain ait puisé ses sources dans les Gesta. Par contre, ce ne peut être le cas de la plus ancienne chronique russe dite Chronique de Nestor.

Selon ce document, rédigé dans sa version définitive au début du XII ${ }^{\mathrm{e}}$ siècle, les Hongrois, après avoir franchi les Carpathes «en l'an 6406» (898 de notre ère), trouvèrent en Transylvanie des «Slovènes», c'est-à-dire des Slaves, et des "Volochs» (en vieux slave, "Volokhove»). Ces "Volochs» étaient alors l'ethnie dominante et c'est celle-ci que les Hongrois durent combattre et chasser du pays transylvain ${ }^{36}$. Il nous semble difficile de considérer que "Voloch" n'est pas synonyme de "Valaque» 37! Indéniablement, tous ces textes, Chronique du Prêtre de Dioclée, P. Magistri Gesta Hungarorum, Anonymi Descriptio Europae Orientalis, Chronique de Nestor, mais aussi le chapitre 187 des Conseils de Kékauménos, disent à peu près la même chose: les Valaques, pastores Romanorum ou Daces romanisés, peuplaient des territoires de l'ancienne Pannonie à l'époque où les Magyars franchirent les Carpathes. Chassés par ce peuple de la steppe, les Valaques émigrèrent au sud du Danube jusque vers la côte dalmate pour les uns, l'Épire, la Thessalie et la Macédoine pour les autres.

Deux siècles plus tard, les Valaques établis au sud du Danube apparaissent dans ce qui peut être considéré comme la période la plus glorieuse de leur histoire. Trois frères, Pierre, Asen, Joannitsa (ou Kalojan), prennent la tête d'un soulèvement contre la domination byzantine en 1185, qui est à l'origine de la formation du second Empire bulgare ${ }^{38}$. Pour l'historien byzantin Nicétas Choniatès qui est notre principale source sur ces événements, les Valaques étaient autrefois appelés les

34 Ibidem, p. 12-13: "Notandum quod inter Machedoniam, Achayam et Thesalonicam est quidam populus valde magnus et spaciosus qui vocantur Blazi, qui et olim fuerunt Romanorum pastores, ac in Ungaria ubi erant pascua Romanorum propter nimiam terre viriditatem et fertilitatem olim morabantur. Sed tandem ab Ungaria inde expulsi, ad partes illas fugierunt; habundat enim caseis optimis, lacte et carnibus super omnes nationes. Terram enim horum Blachorum..."

35 Ibidem, p. 44: "Panoni autem, qui inhabitabant tunc Panoniam, omnes erant pastores Romanorum, et habebant super se decem reges potentes in tota Messia (la Mésie?) et Panonia, deficiente autem imperio Romanorum egresi sunt Ungari de Sycia (la Scythie) provincia et regno magno, quod est ultra Meotidas Paludes..."

Pov'est vrem'ennikh let. I, Moskva-Leningrad, 1950, c. 21.

WINDISCH, "Herkunft", p. 55.

Sur ces événements, Nicétas Choniatès I, p. 368, 47-p. 369, 69; G. OSTROGORSKY, Histoire de l'État byzantin, éd. fr., Paris, 1969, p. 426-429; R.L. WOLFF, " The Second Bulgarian Empire. Its origin and history to 1204”, Speculum 24/1 (1949), p. 167-206. 
Mésiens ${ }^{39}$. Ce sont des Barbares, très proches des Coumans des steppes du BasDanube chez qui ils se réfugient et avec qui ils s'allient pour combattre les Byzantins ${ }^{40}$. Plus tard, après la restauration de l'État bulgare, les armées de l'Empire latin de Constantinople auront fort à faire avec les guerriers de Joannitsa. Or, dans les chroniques de Guillaume de Villehardouin et de Robert de Clari, il est fait bien plus souvent mention des «Blaches» que des «Bougres» 41.

C'est sur le rôle des Valaques dans la renaissance d'un Empire bulgare à la fin du XII e siècle et au début du XIII ${ }^{e}$ qu'eut lieu, dans les années 1920-1940, la rude controverse entre historiens roumains et bulgares ${ }^{42}$. Nous examinerons plus loin les circonstances de la polémique. Notons cependant dès maintenant que savants bulgares et roumains s'affrontèrent sur le sens à donner au terme "valaque». Les Valaques étaient-ils des pasteurs transhumants dont la langue pouvait être aussi bien slave que romane ou étaient-ils une ethnie caractérisée avant tout par leur origine et leur parler latins? La première thèse était évidemment celle des Bulgares tandis que la seconde était celle des Roumains. Il convient de retenir à ce stade de notre enquête que même le mot "valaque» est susceptible d'être interprété de manière tout à fait différente selon les époques et selon les régions balkaniques. C'est ainsi que les populations essentiellement serbes qui se réfugient sur les confins croates, fuyant les armées ottomanes, entre les XVI e et XVIII siècles, sont appelées dans les documents autrichiens, "Wallachen» ${ }^{43}$. Par contre, les Valaques qui jouent un rôle important dans l'histoire de la Bosnie à la fin du Moyen Âge semblent bien être de langue romane ${ }^{44}$.

L'ambiguïté du terme même de "valaque» va peser sur la controverse entre "continuistes» et "discontinuistes». Autant que la rareté et l'apparente imprécision des documents écrits sur ce qui est la question centrale: "Quelle est l'origine des Roumains?»

\section{Roesler et la première phase scientifique de l'histoire de la controverse}

Nous avons pu constater qu'à la fin du siècle des Lumières, le dossier des sources écrites concernant l'ethnogénèse des Roumains ou Valaques était bien connu des érudits spécialistes de la question. Les intellectuels uniates signataires du Supplex

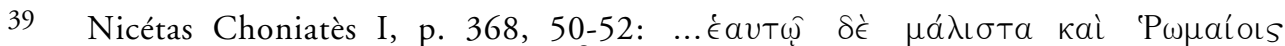

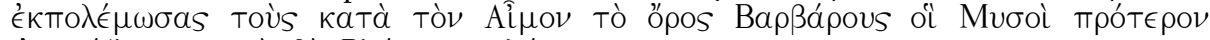

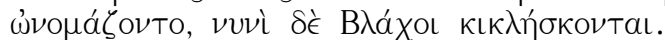

40 Nicétas Choniatès I, p. 374, 79-87; R.L. WOLFF, “Second Bulgarian Empire”, p. 183 et 198-201.

41 OSTROGORSKY, État byzantin, p. 427, n. 1.

42 WOLFF, "Second Bulgarian Empire", p. 174-182 et la longue note de cet auteur, n. 38, p. 182-183, sur la bibliographie et les étapes de cette controverse.

43 A. BLANC, La Croatie occidentale. Étude de géographie humaine, Paris, 1957, p. 95-102.

44 T. MUDRY, Histoire de la Bosnie-Herzégovine. Faits et controverses, Paris, 1999, p. 56-61. 
Libellus Valachorum avaient fièrement revendiqué Trajan et ses légionnaires comme les pères de la nation roumaine en gestation. Et déjà, les adversaires de l'école «latiniste» roumaine avaient répondu par des critiques à la fois pertinentes et passionnées ${ }^{45}$. La période qui suit est décisive: l'âge romantique, si important dans le renouvellement des études historiques européennes ${ }^{46}$, voit l'irruption des Daces, jusqu'alors bien oubliés, dans la controverse. Et les Daces, dont la barbarie horrifiait aussi bien Lactance au IV siècle ${ }^{47}$ que Kékauménos au XI ${ }^{\mathrm{e}}$ siècle ${ }^{48}$ ne pouvaient séduire au départ que des érudits allemands de la mouvance des frères Grimm. Ce furent, comme ceux-ci, deux frères, Arthur et Albert Schott, qui, semble-t-il, furent les premiers à tenter de réhabiliter le grand peuple sujet des rois Burébista et Décébale dans un ouvrage publié en 1845 , les Contes valaques ${ }^{49}$. Cet ouvrage s'inscrit dans ce mouvement européen de retour aux sources des cultures populaires. L'hypothèse de «l'origine dace» des Roumains est reprise, un peu plus tard, par les intellectuels d'un État roumain en gestation à l'est des Carpathes. C'est en effet dans la première moitié du XIX ${ }^{\mathrm{e}}$ siècle que les deux principautés de Valachie et de Moldavie se dégagent peu à peu du protectorat ottoman pour former un royaume de Roumanie indépendant 50 . Selon Lucian Boia, le premier savant roumain à affirmer l'origine dace des Roumains est Bogdan Hasdeu, linguiste et historien, en $1860^{51}$. Mais, en fait, avec Hasdeu, la controverse est entrée dans une phase décisive de son histoire, une phase scientifique, "positiviste» pour être plus précis!

En 1866, paraissait la première étude d'un historien autrichien, Robert Roesler, qui allait devenir le maître à penser de l'école «discontinuiste», sur la question de la filiation entre Daces de l'Antiquité et Roumains de l'époque contemporaine ${ }^{52}$. Par la suite, Robert Roesler publiait en 1871 un ouvrage plus approfondi sur cette même question ${ }^{53}$. On peut critiquer Roesler (et, comme on le verra, ce fut bien souvent le cas), estimer que son œuvre participait de l'hypercriticisme du milieu du XIX ${ }^{\mathrm{e}}$ siècle dont faisait preuve Jakob-Philipp Fallmerayer sur le problème de la continuité du

\footnotetext{
Ainsi G. SULZER, Geschichte der transalpinischen Daciens, Vienne, 1782. J. EHRARD et J. PALMADE, L'Histoire, Paris, 1964, p. 52-66.

Lactance, De la mort des persécuteurs éd. et trad. J. MOREAU, Paris, Éditions du Cerf, coll. Sources chrétiennes, 1954, t. I, IX, 2; XXIII, 5; XXVII, 8, où l'écrivain chrétien explique la sauvagerie de l'empereur Galère par ses origines daces.

48 Cf. supra, n. 18.

49 Albert et Arthur SCHOTT, Walachische Märchen..., Stuttgart-Tübingen, 1845, trad. fr. Contes roumains, Paris, 1982, cités in A.-M. THIESSE, La création des identités nationales. Europe XVIII'-XXe siècles, Paris, 1999, p. 96-100.

50 Sur ce processus: D URANDIN, Roumains, p. 93-160.

51 BOIA, Roumanie, p. 45.

52 R. ROESLER, "Dacier und Romänen. Eine geschichtliche Studie", Sitzungsberichte der philosophisch-historischen Classe der kaiserlichen Akademie der Wissenschaften 53 (1866), 53 p.9-92.

53 R. ROESLER, Romänische Studien. Untersuchungen zur älteren Geschichte Romäniens, Leipzig, 1871.
} 
peuplement hellénique dans le sud de la péninsule balkanique ${ }^{54}$. Mais, comme l'écrit Rudolf Windisch, il n'est pas si facile encore actuellement d'ignorer ses arguments, de même qu'il faut lui reconnaitre le mérite d'avoir pour la première fois dans l'histoire de la controverse utilisé les apports de la linguistique, de la toponymie et de l'archéologie 55 .

Résumer la thèse «anti-continuiste» de Roesler en quelques points n'est pas chose aisée! Mais la conclusion de l'article paru en $1866^{56}$ et le résumé proposé par Rudolf Windisch sont susceptibles de nous y aider ${ }^{57}$. Le premier argument invoqué pour nier la continuité d'un peuplement roman sur le territoire de l'ancienne Dacie de la fin de l'Antiquité à l'époque contemporaine est l'argument ex silentio: il n'existe aucune source écrite qui prouve l'existence de populations de langue romane durant un espace de temps d'un millier d'années au nord du Danube ${ }^{58 !}$ Le deuxième argument est remarquablement moderne et s'appuie sur les données toponymiques: les noms de lieux hérités du Moyen Âge sont d'origine magyare (en Transylvanie) ou slaves (en Transylvanie, Banat, Valachie, Moldavie), mais aucun d'eux n'est roman. Il est caractéristique pour Roesler que les hydronymes, par nature plus conservateurs que les toponymes, n'ont subsisté que par l'entremise du hongrois 59 .

Mais c'est surtout la linguistique qui est utilisée pour prouver ce qui est le corps même de la thèse de Roesler, à savoir l'origine sud-danubienne des Valaques du Moyen Âge et des Temps Modernes. Roesler constate dans les parlers daco-roumain, macédo-roumain et istro-roumain l'absence de termes d'origine gothique, coumane et petchenègue. En effet, si les ancêtres des Roumains avaient vécu au nord du Danube, ils auraient longtemps été au contact d'abord des Wisigoths, puis des peuples touraniens qui ont nomadisé durant des siècles de la Bessarabie à la "Puszta" hongroise et, par conséquent, influencés fortement sur le plan linguistique ${ }^{60}$. Par contre, la parenté, (indiscutable il est vrai, entre roumain et albanais, tant dans le domaine du vocabulaire que dans celui de la syntaxe, la forte influence bulgare aussi exercée sur les Roumains et Aroumains, plaident en faveur d'une ethnogénèse opérée quelque part dans la péninsule balkanique ${ }^{61}$. La cause est donc entendue et le scénario mis au point.

\footnotetext{
54 J.Ph. FALLMERAYER, Geschichte der Halbinsel Morea während des Mittelalters, t. I-II, Stuttgart, 1830-1836.

55 WINDISCH, "Herkunft", p. 51

56 ROESLER, “Dacier”, p. 78-80.

57 WINDISCH, "Herkunft", p. 51-52.

58 ROESLER, “Dacier ”, p. 80, (argument f): "Siebenbürgen und die Donaufürstentümer sind keine romanischen, sondern sehr spät partiell romanisierte Länder. Die Continuität der romanischen Bevölkerung im Lande ist durch ein Jahrtausend unterbrochen»; Romänische Studien, p. 66 et 99.

59 ROESLER, "Dacier", p. 79-80 (argument $e$ ).

60 ROESLER, "Dacier ”, p. 80 (argument $g$ ); Romänische Studien, p. 123.

61 ROESLER, "Dacier ", p. 79 (arguments b et $d$ ); Romänische Studien, p. 125-129.
} 
Lors de la conquête de la Dacie par l'armée de Trajan, les indigènes ont été exterminés ou chassés de leur terre natale. Ils ont été remplacés par des colons venus de tout l'Empire romain ${ }^{62}$. Les Valaques ou Roumains ne peuvent donc être les descendants des Daces! En 275, toute la population romaine de Dacie fut évacuée au sud du Danube et implantée dans ce qui devint les provinces de Dacia Ripensis et Dacia Mediterranea. La version de Flavius Vopiscus est donc préférée aux autres et vraiment prise «au pied de la lettre» 63 ! Ces colons sont les véritables ancêtres des Valaques ou Roumains de l'époque moderne ${ }^{64}$.

Il pouvait être objecté à Roesler que certains textes, parmi lesquels se trouvaient les premiers documents écrits de la nation magyare, mentionnaient des Blachii ou "Volochs" dans la région carpathique à l'époque même où les compagnons d'Arpad envahissaient celle-ci. On l'a vu précédemment. Il s'agit de la Gesta Hungarorum et de la Chronique de Nestor ${ }^{65}$. Or Roesler refuse catégoriquement de reconnaître l'historicité de ces sources ${ }^{66}$. Sur le problème de la valeur historique à accorder à la plus ancienne chronique hongroise, il est piquant de remarquer qu'à la suite de Roesler les historiens magyars la considèrent comme purement légendaire et très peu fiable, alors que les historiens roumains en font grand cas 67 !

Mais si les Valaques ou Roumains sont les descendants des colons romains des Dacies cisdanubiennes, il reste à établir la chronologie et les circonstances de leur retour dans les anciennes Dacies transdanubiennes devenues les Transylvanie, Valachie et Moldavie médiévales, puis modernes! Or, il n’existe aucune source écrite mentionnant le "grand retour» des Roumains sur la terre de leurs ancêtres. Roesler tourne la difficulté en considérant que ce mouvement migratoire s'est fait au XIII siècle par infiltration de groupes transhumants, hors donc du champ d'observation des chroniqueurs byzantins et latins d'Occident. Les Valaques, du fait de l'insécurité généralisée due aux invasions avaro-slaves et bulgares de la fin de l'Antiquité et du début du Moyen Âge, étaient revenus à un genre de vie pastoral et semi-nomade,

62 Eutrope VIII, 6, 2, p. 104-105: "Idem (l'empereur Hadrien) de Dacia facere conatum (évacuer la Dacie!) amici deterruerunt ne multi cives Romani barbaris traderentur propterea quia Traianus victa Dacia ex toto orbe Romano infinitas eo copias hominum transtulerat ad agros et urbes colendas. Dacia enim diuturno bello Decibali viris fuerat exhausta."

63 ROESLER, Romänische Studien, p. 67.

64 ROESLER, "Dacier”, p. 79 (argument d: «Sie (les Valaques) sind die Nachkommen der zablreichen Ansiedler Roms, die aus dem Trajanischen Dacien in das Aurelianische Dacien verplanzt...»).

65 Cf. supra, n. 26 et 36.

66 ROESLER, Romänische Studien, p. 79-85.

67 I. BONA, in Histoire de la Transylvanie, p. 114-116; V. CRISTIAN, A. DEAC, N.E DROIU, "Un jeu dangereux: la falsification de l'Histoire”, in Un jeu dangereux, p.66. 
traditionnel dans les montagnes balkaniques ${ }^{68}$. C'est la théorie de la «patrie mobile» des Proto-Roumains, chère à l'historiographie hongroise ou magyarophile ${ }^{69}$.

L'utilisation par Roesler des données linguistiques et toponymiques pour argumenter sa théorie "immigrationniste» fait incontestablement date dans l'histoire de la controverse. Mais sa position à l'égard des sources écrites, typique d'un certain hypercriticisme historiographique du milieu du XIXe siècle, laissait la place à une contre-offensive de la partie adverse qui n'a pas tardé d'ailleurs! Il ne faut pas oublier également le contexte historique des années 1866-1871, époque durant laquelle Roesler fait paraitre ses travaux les plus importants. 1866, c'est l'année de Sadowa. En 1867, l'empereur François-Joseph fait le choix, décisif, du dualisme austro-hongrois qui voit l'émergence d'un État national hongrois particulièrement offensif à l'égard des nationalités non-magyares, notamment à l'égard de la communauté roumaine de Transylvanie ${ }^{70}$. À la même époque, les principautés de Valachie et de Moldavie se libèrent progressivement de la tutelle ottomane et s'engagent dans un processus de réunification qui conduit à la formation d'un royaume unitaire de Roumanie ${ }^{71}$.

Un savant autrichien, Julius Jung, fut un des premiers à s'élever contre la théorie de Roesler ${ }^{72}$, ce qui prouve bien que la ligne de démarcation entre "continuistes» et «immigrationnistes» ne se confond pas nécessairement avec celle entre les diverses nationalités. La plupart des historiens roumains de la fin du XIX ${ }^{\mathrm{e}}$ siècle sont certes "continuistes", mais l'un d'entre eux, et pas le moindre, le moldave Alexandru Philippide, fut un ferme partisan de l'origine sud-danubienne des Roumains. Il est cependant vrai que la première véritable génération d'historiens roumains fut dans son immense majorité "continuiste». Ce fut le cas, notamment, de Bogdan Hasdeu et d'Alexandru Xenopol 73. Mais ces deux savants ne s'accordaient pas sur le lieu de formation du peuple roumain au nord du Danube. Celui-ci était à chercher pour Hasdeu du côté de la Valachie, plus exactement l'Olténie, tandis que les préférences

68 ROESLER, "Dacier ”, p. 80 (argument j: " Die Rückwanderung der Walachen ist sehr im Dunkel, weil sie eine allmählige Nordbewegung wandernder Hirten war; unmerklich in ihren Anfängen, geräuschlos in ihrem Ablauf. Die Wanderung nach Siebenbürgen und der Fürstenthümern (de Valachie et de Moldavie) ist nur die grösste und erfolgreichste der romänischen Wanderungen.»).

69 L. MAKKAI, "La naissance de la société d'Ordres (1172-1526)", in Histoire de la Transylvanie, p. 181-186.

70 V.L. TAPIE, Monarchie et peuples du Danube, Paris, 1969, p. 334-338 et p. 364 («1866, 1871 , dates de profonds changements dans la structure de l'Europe et les rapports des puissances entre elles.»); J. BERENGER, Histoire de l'Empire des Habsbourg (12731918), Paris, 1990, p. 640-660.

71 DURANDIN, Roumains, p. 139-182; B OIA, Roumanie, p. 95-122.

72 J. JUNG, "Die Anfänge der Rumänen", Zeitschrift für das österreichische Gymnasium 27 (1876), p. 1-19; 86-109; 321-342.

73 B.P. HASDEU, Istoria criticã a Românilor [Histoire critique des Roumains], Bucarest, 1873; A.D. X ENOPOL, Une énigme historique: les Roumains au Moyen Âge, Paris, 1885. 
de Xenopol allaient à la Transylvanie ${ }^{74}$. Un troisième historien roumain, Dimitrie Onciul, à la même époque, consacra toute une étude à la théorie de Roesler ${ }^{75}$. Onciul pensait qu'il ne convenait pas d'être lié par l'alternative radicale imposée par les «continuistes» et "immigrationnistes» de rechercher la patrie des Proto-Roumains, soit au nord, soit au sud du Danube. Le berceau national du peuple roumain avait pu très bien se situer sur les deux rives du Danube, donc aussi bien en Dacie transdanubienne qu'en Dacie cisdanubienne (cf. planche 1). Le Danube, au niveau des Portes de Fer, n'était pas une frontière, mais l'axe central de toute une Romania tardo-antique et médiévale, conception certes extrêmement intéressante et novatrice, mais qui ne pouvait que très mal s'accorder avec la formation d'états nationaux très jaloux de l'intangibilité de leurs frontières! En l'occurrence, il s'agissait de la frontière entre la Roumanie et le tout nouvel État bulgare.

Mais les «immigrationnistes» ne désarmaient pas! Au contraire, ils affinaient leurs arguments. Il est difficile de rendre compte en quelques lignes de tous leurs travaux. Cependant, de ceux-ci se dégagent quelques caractères d'ensemble. Si l'on excepte les Roumains Ovid Densusianu et Alexandru Philippide, la plupart des savants qui se sont élevés contre la théorie de la continuité romano-roumaine dans les pays transdanubiens sont allemands, autrichiens ou hongrois. Les linguistes tiennent la première place dans le débat scientifique. Cette place est tout à fait logique. À la suite de Roesler, les «immigrationnistes» considèrent qu'il n'existe pas de source écrite susceptible de rendre compte de la migration des Proto-Roumains au nord du Danube et que par conséquent, il est nécessaire de recourir aux «sciences auxiliaires de l'histoire». Mais, parmi celles-ci, l'archéologie, n'étant qu'à ses débuts dans cette partie de l'Europe, ne peut pas être d'une grande utilité. Il ne reste donc que la linguistique, laquelle, comprise dans la philologie, est la «science-reine» des universités germaniques!

Presque tous les «immigrationnistes» insistent sur la parenté linguistique entre roumain et albanais. Ils déduisent de ce fait que les deux peuples ont vécu dans une même région pendant une période relativement longue. Il faut donc chercher cette région dans la partie des Balkans la plus anciennement peuplée par les Albanais ${ }^{76}$. Or, sur ce point précis, la controverse sur les origines du peuple roumain rejoint une autre controverse qui porte sur l'ethnogénèse des Albanais et qui n'est pas moins

BOIA, Roumanie, p. 62-63.

D. ONCIUL, Teoria lui Roesler [La théorie de Roesler], Bucarest, 1885.

Un des meilleurs exposés sur ce problème peut être trouvé dans M. FRIEDWAGNER,

"Über die Sprache und Heimat der Rumänen in ihrer Frühzeit", Zeitschrift für Romanische Philologie 54 (1934), p. 654-656; 664- 666; 686-687; 714-715. 
complexe ni passionnée ${ }^{77}$ ! C'est vers le milieu du XIX ${ }^{\mathrm{e}}$ siècle que des savants allemands et autrichiens découvrent (ou redécouvrent!) les Albanais et posent à propos de cette ethnie balkanique également le problème de son identité et de son "autochtonéité» sur le vaste territoire qu'elle occupait à cette époque ${ }^{78}$. Fallmerayer et von Hahn avaient tendance à penser que les Albanais étaient le peuple le plus anciennement établi dans les Balkans, sans doute même descendant des mythiques Pélasges ${ }^{79}$ !

Très logiquement, beaucoup parmi les « immigrationnistes» considérèrent que le berceau originel des Valaques coïncidait avec les régions peuplées par les Albanais. Pour les grands historiens balkanologues «autrichiens» que furent Franz Miklosich, Wilhelm Tomaschek et Konstantin Jirecek, les Valaques se constituèrent en ethnie au contact des Albanais dans une vaste zone s'étendant du nord de l'Albanie et de la

77 Sur cette "autre» controverse concernant le sud-est de l'Europe, cf. parmi l'abondante littérature albanaise (donc favorable à la thèse de la continuité entre Illyriens et Albanais), Sk. ANAMALI, "Nga Ilirët tek Arbërit (Të dhëna të reja të arkeologjisë)" [Des Illyriens aux Arbères (Nouvelles données de l'archéologie)], Iliria 1 (1985), p. 211-218 et résumé en français; contra, cf. le recueil d'articles yougoslave Iliri $i$ Albanci [Illyriens et Albanais], dir. M. GARASHANIN, Académie serbe des Sciences et des Arts, Belgrade, 1988, en serbe et français et plus récemment, G. SCHRAMM, Anfänge des albanischen Christentums. Die frühe Bekehrung der Bessen und ihre langen Folgen, Freiburg im Brisgau, $2^{\mathrm{e}}$ éd., 1999; mise au point récente de la question par A. DUCELLIER, "Les Albanais dans l'Empire byzantin: de la communauté à l'expansion”, in OiJ Albanoi; sto; Mesaivwna [Les Albanais au Moyen Âge], Athènes, 1998, p. 17-45.

78 J.Ph. FALLMERAYER, "Das albanesische Element", Abhandlungen der Historischen Classe der Königlich-Bayerischen Akademie der Wissenschaften, München, 1. Abt.: "Über Ursprung und Altertum der Albanesen”, 1857, Bd. 8, p. 417-487; Ibid., 2. Abt.: "Was man über die Taten und über die Schicksale des albanischen Volks von seinem ersten Auftreten in der Geschichte bis zu seiner Unterjochung durch die Türken nach dem Tode Skanderbegs mit Sicherheit wissen kan», 1860, Bd. 8, p. 658-736; J.G. VON HAHN, Albanesische Studien, Iena, 1854; Reise durch die Gebiete des Drin und Wardar, (Denkschriften der Kaiserlichen Akademie der Wissenschaften, PhilosophischHistorische Classe), Wien, 1867, 15. Bd., 1. Abt., 1869, 16. Bd., 2. et 3. Abt.; G.S TADTMÜLLER, Forschungen zur albanischen Frühgeschichte, (travail universitaire présenté à Breslau en 1936), rééd. Wiesbaden, 1966.

79 VON HAHN, Albanesische Studien, p. 211-279; tout à fait récemment, cette thèse a été reprise par M. AREF, Albanie (Histoire et langue) ou l'incroyable odyssée d'un peuple préhellénique, Paris, 2003. 
Macédoine à la Syrmie et à la vallée du Timok ${ }^{80}$. Les historiens hongrois, quant à eux, furent davantage enclins à soutenir l'hypothèse de l'origine italienne et dalmate. Typique à cet égard fut l'étude que consacra Lájos Thallóczy à la " wlachische Frage» en $1901{ }^{81}$. Thallóczy avait l'originalité de ne pas être un historien "de profession", mais était un haut fonctionnaire du ministère des Finances austro-hongrois. À ce titre, il fut, en 1912, chef de division au bureau bosniaque de ce ministère, puis en 1915 gouverneur civil de la Serbie occupée par l'armée de la Double Monarchie ${ }^{82}$.

Dans son article sur «La question valaque ou roumaine», Thallóczy part du postulat selon lequel la thèse de l'origine balkanique et pastorale des Valaques n'est plus à démontrer depuis les travaux des " austro-allemands" Thunmann, Kopitar, Miklosich, Jirecek, Jung, Pic, Roesler, Tomaschek et ceux des Hongrois Paul Hunfalvy, Ladislas Réthy ${ }^{83}$. C'est en fait ce dernier historien que suit et précise Thallóczy. Dans un gros ouvrage paru à Budapest en $1898^{84}$, Réthy soutient que l'origine des Valaques est à rechercher en Dalmatie, là où la romanisation fut ancienne et profonde. Mais il n'y aurait pas eu cette ethnogénèse sans l'arrivée progressive de bergers d'Italie centrale, plus précisément des Apennins, migrant par le Frioul et s'installant au milieu de populations «illyriennes» (les ancêtres des Albanais selon Thallóczy ${ }^{85}$ ) et slaves vers les VIIe-VIIIe siècles. Les dialectes de ces bergers auraient alors subi de fortes influences «illyriennes» et slaves et auraient ainsi donné naissance à la langue roumaine. Les arguments de Réthy et de Thallóczy sont essentiellement linguistiques. La langue roumaine serait très proche des dialectes du centre de l'Italie et de la Sardaigne ${ }^{86}$. Des critères culturels interviennent ensuite: la vie pastorale dans

$80 \quad$ F. MIKLOSICH, Über die Wanderungen der Rumunen in den Dalmatinischen Alpen und den Karpaten, (Denkschriften der kaiserlichen Akademie der Wissenschaften, Philosophisch-historische Classe, 30. Bd.), Vienne, 1880, p. 6: "Aus dem gesagten ergibt sich, dass die Rumunen von einem Punkte der Haemus-halbinsel in serbisches Gebiet und da gegen Norden in von Kroaten bewohnte Gegenden eingedrungen sind, nicht in grossen Massen, sondern als Wanderhirten in kleinen Gruppen, daher ohne Aufsehen zu erregen, unbermerkt von den Chronisten."; W. TOMASCHEK, "Zur Kunde der HämusHalbinsel I: 6. Wo befanden sich die ehemaligen Hauptsitze der Wlachen?", Sitzungsberichte der Philosophisch-historischen Classe der kaiserlichen Akademie der Wissenschaften, Vienne, 1882, p. 492-498; K. JIRECEK, Die Romänen in den Städten Dalmatiens während des Mittelalters, (Denkschriften, 48. Bd.), Vienne, 1902, p. 20-21.

81 D'abord paru en hongrois dans le Budapesti Szemle 1907-1908 (1901), cette étude fut publiée en allemand dans le recueil des Illyrisch-albanische Forschungen, dir. L.T HALLÓCZY, Munich-Leipzig, 1916, sous le titre suivant: "Die Theorie der wlachischen oder rumänischen Frage”, p. 38-62.

82 MUDRY, Bosnie, p. 253.

83 THALLÓCZY, “Die Theorie”, p. 39.

84 L. RETHY, Der Romanismus in Illyricum, Budapest, 1898.

85 M. PILLON, "Nos ancêtres les Illyriens: continuité illyro-albanaise et affirmation de l'identité nationale dans l'Albanie d'Enver Hoxha", in Retrouver, imaginer, utiliser l'Antiquité (Actes du colloque international tenu à Carcassonne les 19 et 20 mai 2000), dir. S. CAUCANAS, R. CAZALS, P. PAYEN, Toulouse, 2001, p. 62-63.

86 THALLÓCZY, "Die Theorie", p. 39-40. 
les Apennins depuis l'époque de Varron jusqu'à celle de Réthy et de Thallóczy est tout à fait identique à la vie pastorale dans les Balkans 87 ! Thallóczy avoue même - un peu naïvement... et brièvement - que les textes manquent sur cette migration pastorale d'Italie vers les Carpathes via la Dalmatie. Celle-ci ne peut être prouvée directement, mais indirectement ${ }^{88}$ ! De toute manière, «la recherche linguistique doit primer» ${ }^{89}$.

L'étude de Lájos Thallóczy est tout à fait caractéristique de la recherche historique «immigrationniste» des années précédant la Première Guerre mondiale: primat de la linguistique, rejet (ou même ignorance) des rares sources écrites pouvant infirmer la thèse de la migration des Proto-Roumains des Balkans vers la Transylvanie, la Valachie et la Moldavie. Le conflit de 1914-1918, sur ces entrefaits, modifia complètement les données géopolitiques dans le sud-est de l'Europe et ne pouvait pas manquer d'avoir des conséquences importantes sur la controverse entre «immigrationnistes» et «continuistes».

\section{L'apogée de la controverse}

On sait ce que le premier conflit mondial et surtout les traités de paix qui l'ont suivi ont eu pour conséquences au nord et au sud de la basse vallée du Danube. Le rapport de forces fut complètement bouleversé: disparition des empires d'origine supranationale comme l'Empire austro-hongrois et l'Empire ottoman, avènement d'une "Grande Roumanie» 90 et d'une "grande Serbie» (sous la forme masquée d'un royaume unitaire de Yougoslavie), abaissement de la Bulgarie qui avait choisi le mauvais camp. Il semble surtout qu'a alors triomphé le principe de l'État national sur celui de l'empire universel. Très rapidement, l'œuvre des traités est critiquée par les "révisionnistes», notamment hongrois ${ }^{91}$ et bulgares 92 dans cette partie de l'Europe. La controverse aura dorénavant comme arrière-plan géopolitique et idéologique les tensions entre "États successeurs" bénéficiaires des traités et "États successeurs" révisionnistes ${ }^{93}$. Un des grands historiens roumains du moment, Gheorghe Brătianu, ne s'y est du reste pas trompé: la controverse n'a jamais été innocente ${ }^{94 !}$

THALLÓCZY, "Die Theorie", p. 41-57.

THALLÓCZY, "Die Theorie", p. 39.

THALLÓCZY, "Die Theorie", p. 62.

BOIA, Roumanie, p. 122-129.

J. BERENGER, Lexique historique de l'Europe danubienne, Paris, 1976, s.v. «Révisionnisme hongrois», p. 211-212.

92 B. LORY, "Bulgarie: la permanence de la question nationale", Historiens et Géographes 329 (1990), p. 81-87.

93 J. BERENGER, L'Europe danubienne de 1848 à nos jours, Paris, 1976, p. 145-148.

94 G.I. BRÃTIANU, Une énigme et un miracle historique: le peuple roumain. À propos du livre de M. Ferdinand Lot sur les invasions barbares et de quelques ouvrages récents sur les origines du peuple roumain, Bucarest, 1937, p. 5-7. 
On peut considérer que, par bien des aspects, la période de «l'entre-deuxguerres» voit l'apogée de la controverse. Elle atteint à cette époque sa plus grande intensité, de par la production en articles et en ouvrages la concernant, mais aussi de par la virulence des propos échangés. Elle se signale aussi par la qualité des intervenants. Nous retrouvons à un niveau toujours très honorable les savants des universités germaniques: Gustav Weigand, Ernst Gamillscheg, Karl Patsch, Walther von Wartburg, Matthias Friedwagner, toutes personnes dont Gheorghe Brătianu loue la rigueur scientifique et l'honnêteté ${ }^{95}$. Les Hongrois, désormais constitués en école historique indépendante $\mathrm{du}$ monde austro-allemand, sont toujours les «immigrationnistes» les plus actifs et souvent les plus agressifs. Les noms qui dominent à Budapest sont ceux de János Székely, András Alföldi, Lájos Gáldi, László Makkai, et surtout de Lájos Támas. Mais le phénomène le plus marquant, c'est le rôle de premier plan joué par les écoles nationales de Roumanie et, secondairement, de Bulgarie.

Deux noms dominent en Roumanie la recherche historique des années 19201940, ceux de Gheorghe Brãtianu, déjà cité, et de Nicolae Iorga. Ces personnages présentent des traits communs: ce sont tout à la fois des écrivains, des érudits, des historiens, des hommes politiques dont la carrière et l'existence se sont tragiquement achevées par une mort violente ${ }^{96}$, d'infatigables voyageurs et hommes d'action ${ }^{97}$. Tous les deux écrivent aussi bien en français qu'en roumain, comme tant d'intellectuels de leur pays en ce temps-là. La Bulgarie n'est pas en reste. Elle présente l'équivalent de Iorga et de Brãtianu en la personne de Vasil Nikolov Zlatarski, le grand historien de la Bulgarie médiévale ${ }^{98}$. Zlatarski ne s'est pas exprimé en français comme ses collègues roumains, mais, ayant fait une partie de ses études à SaintPétersbourg et à Berlin ${ }^{99}$, il eut une solide formation en russe et en allemand. Par contre, l'autre grand historien bulgare qui intervint dans la controverse, Peter Mutafciev, écrivit en français.

Le français est d'ailleurs, à côté de l'allemand, une «langue internationale» très utilisée dans les débats entre «immigrationnistes» et "continuistes» entre 1920 et 1940. Cette place se comprend certes par le rôle joué par la France sur les plans diplomatique et militaire, par son prestige aussi, dans cette partie de l'Europe. La

BRÃTIANU, Énigme, p. 35, n. 1.

Nicolae Iorga fut assassiné par les Gardes de Fer en 1940. Gheorghe Brãtianu fut déporté dans un camp de travail stalinien où il mourut en 1953. Cf. BOIA, Roumanie, p. 152 et 326.

97 Cf. les intéressantes notes de voyage de N. IORGA, Cãlātorii peste hotare [Voyages audelà des frontières], 2 tomes, parues d'abord en 1895 et 1939, nouvelle éd. Bucarest, 1980.

98 Une introduction à la vie et à l'œuvre de ce grand savant se trouve chez V. TÃPKOVAZAÏMOVA, "Vasil Zlatarski et son héritage historique", in Byzance et les Balkans à partir $d u V^{e}$ siècle, (Variorum Reprints), Londres, 1979, p. 79-86.

99 TÃPKOVA-ZAÏMOVA, “Zlatarski”, p. 79-80. 
Roumanie, d'autre part, au niveau surtout de ses élites politiques et culturelles, est un pays alors quasiment francophone ${ }^{100}$. Mais même dans des pays comme la Hongrie et la Bulgarie pourtant sous influence germanique, paraissent des articles et des ouvrages rédigés ou traduits en français concernant la controverse ${ }^{101}$. Les Français eux-mêmes interviennent et c'est l'un d'entre eux, le grand médiéviste Ferdinand Lot, qui, par sa prise de position en faveur de la théorie de l'immigration, déclenchera une belle "empoignade» parmi les spécialistes de la question ${ }^{102}$ ! Les Britanniques, eux aussi, se risquent dans l'arène avec notamment Robert William Seton-Watson ${ }^{103}$.

La production scientifique de cette époque, relative à la controverse, se signale tout d'abord par le perfectionnement des instruments de recherche, notamment linguistiques. Ainsi furent élaborés, à la veille de la Deuxième guerre mondiale, deux atlas linguistiques roumains qu'a utilisés Ernst Gamillscheg pour délimiter les «KernGebiete» de l'ethnogénèse roumaine ${ }^{104}$. Les fouilles archéologiques débutent aussi, au nord comme au sud du Danube ${ }^{105}$. Certes, on n'évite pas les conclusions hâtives ou tendancieuses. Mais l'«entre-deux-guerres» est sur ce plan la préface de la période qui suivra le conflit de 1939-1945. Enfin, tout savant prenant position pour la thèse de l'immigration ou pour la thèse de la continuité estime nécessaire de récapituler les études qui ont été réalisées sur ce sujet depuis au moins la fin du XVIII e siècle. De ce point de vue, le gros article écrit par Matthias Friedwagner, Allemand de Bucovine (province appartenant à la Roumanie depuis 1920), est extrêmement précis, documenté et impartial ${ }^{106}$.

La thèse de l'immigration bénéficie des travaux de Gustav Weigand, spécialiste des Aroumains et des Albanais. Dans une étude parue en 1927, Weigand tentait de démontrer qu'Albanais et Protoroumains venaient de la même région des Balkans occidentaux, à savoir le triangle limité par les villes de Nä̈ssus (act. Nish en Serbie), Serdica (act. Sofia en Bulgarie) et Scupi (act. Skopje en Macédoine), à partir de

100 BOIA, Roumanie, p. 252-253.

101 Parmi les plus marquants, sur lesquels nous reviendrons nécessairement: P.M UTAFCIEV, Bulgares et Roumains dans l'histoire des pays danubiens, Sofia, 1932; L.T AMÁS, "Romains, Romans et Roumains dans l'histoire de la Dacie Trajane", Archivium Europae Centro-orientalis 1 (1935), p. 1-96, et 2 (1936), p. 46-83.

102 F. LOT, Les invasions barbares et le peuplement de l'Europe. Introduction à l'intelligence des derniers traités de paix, t. I, Paris, 1937, III section: "Une énigme et un miracle historique: le peuple roumain", p. 278-298, titre que reprit, avec quelque ironie, dans sa réponse le savant roumain G.I. Brãtianu. Cf. supra, n. 94.

103 R.W. SETON-WATSON, History of the Rumanians, Londres, 1935.

104 WINDISCH, "Herkunft", p. 64.

105 Cf. les fouilles austro-bulgares sur le territoire de l'ancienne Dacia Ripensis dont le rapport ne sera publié qu'en 1950: H. VETTERS, Dacia Ripensis, (Österreichische Akademie der Wissenschaften, Schriften der Balkankommission, antiquarische Abteilung XI), Vienne, 1950.

106 FRIEDWAGNER, "Über die Sprache”, p. 641-715. 
données essentiellement linguistiques et toponymiques ${ }^{107}$. Ce serait la poussée bulgare au IX $\mathrm{IX}^{\mathrm{e}}$ siècle qui aurait provoqué l'émigration, d'une part des Protoalbanais vers les côtes de l'Adriatique, d'autre part des Protoroumains dans pratiquement toutes les directions 108 ! Mais face à cette opiniâtre obstination à faire venir les ancêtres des Roumains du nord-ouest de la Bulgarie actuelle, s'éleva une toute nouvelle opposition qui était celle des historiens bulgares eux-mêmes. Ces historiens étaient d'autant plus mobilisés que, depuis quelque temps, l'historiographie roumaine s'intéressait particulièrement à l'ancienne Dacia Ripensis, laquelle correspondait aux régions devenues bulgares de Arcar (l'antique Ratiaria) et de Vidin (l'antique Bononia) et avait été le refuge de la population daco-romaine rapatriée par les soins de l'empereur Aurélien.

Incontestablement, la controverse devint alors très complexe. À la querelle entre historiens roumains et hongrois, s'était en effet ajoutée une vive altercation entre historiens roumains et bulgares ${ }^{109 !}$ Que s'était-il donc passé? Un des grands arguments de l'école "immigrationniste» contre la thèse de la continuité entre Dacoromains et Roumains au nord du Danube était la constatation (irréfutable, il est vrai) des très fortes traces de "latin balkanique», en particulier de termes du latin militaire et ecclésiastique utilisé à Byzance entre les IVe et VIIe siècles, et toujours présentes dans le vocabulaire de la langue roumaine. La dénomination même de Rumun/ Romanus (cf. Roum/ Roumi en arabe) pouvait être considérée comme l'héritage d'une longue période durant laquelle s'était formé le peuple roumain... au sud du Danube, dans des Balkans occidentaux et septentrionaux faisant alors partie de l'Empire romain d'Orient ${ }^{110}$.

107 G. WEIGAND, "Sind die Albaner die Nachkommen der Illyrer oder der Thraker?", Balkan-Archiv 3 (1927), p. 227-251.

108 Sauf vers l'est (et encore!). Les futurs Roumains de Transylvanie, Valachie et Moldavie auraient migré vers le nord, les futurs Aroumains d'Épire et de Thessalie vers le sudouest, les ancêtres des Mégléno-Roumains vers le sud et ceux des Morlaques dalmates vers l'Ouest. Il est à noter que la thèse de Weigand a été récemment reprise par SCHRAMM, Anfänge.

109 On pourrait ajouter la controverse sur les origines des Aroumains d'Épire et de Thessalie, dont l'aire de semi-nomadisation a été partagée à partir de 1913 par la frontière albanogrecque. D'une part, les Roumains soutiennent que les Aroumains sont des Roumains détachés du tronc commun depuis le Moyen Âge, tandis que Grecs et Albanais considèrent que «leurs» Valaques sont soit des Grecs latinisés du côté grec, soit des Illyriens latinisés du côté albanais. Donc il a existé (et il existe encore) une controverse gréco-roumaine et une controverse albano-roumaine! Cf. A.G. LAZAROU, L'aroumain et ses rapports avec le grec, Thessalonique, 1986; P. et B. CABANES, Passions albanaises. De Berisha au Kossovo, Paris, 1999, p. 47.

110 ROESLER, "Dacier", p. 79, argument $c$ ): «Die Walachen nennen sich Romänen, Rumunen, weil sie Unterthanen des römischen, d.i. des byzantinischen Reiches waren, gerade so wie die Neugriechen und Bulgaren sich in demselben Sinne und aus demselben

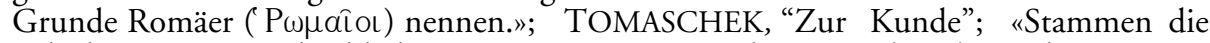
Wlachen von züruckgebliebenen Daco-Romanen ab?», p. 478-492, plus particulièrement p. 486-492. 
Or, après la Première guerre mondiale, des avancées significatives furent faites dans la connaissance du latin parlé et écrit dans le sud-est de l'Europe entre l'époque de la conquête romaine des Balkans et celle des invasions avaro-slaves (Ier-VIIe siècles), grâce notamment aux remarquables travaux du Croate Petar Skok ${ }^{111}$. Les années 1920-1940 furent aussi, on l'a vu, la grande période de l'historiographie roumaine avec les grands noms de Nicolae Iorga et Gheorghe Brătianu. Ces historiens étaient des byzantinistes confirmés. Et ils pensaient que la voie vers l'explication des origines roumaines passait par Byzance. Peut-être même davantage par Byzance que par Rome! Mais une Byzance qui, du IVe au VIIe siècle, parlait et écrivait le latin sur les bords du Danube et dans le nord-ouest de la péninsule balkanique.

Dès les années 1920-1930, avec le style imagé et le romantisme qui le caractérisent, Nicolae Iorga s'est attaché à défendre la thèse des Romaniae d'abord autonomes, puis indépendantes, $\mathrm{du}$ "Danube d'Empire» ${ }^{112}$. L'historien roumain utilise avant tout les récits des historiens byzantins des $\mathrm{V}^{\mathrm{e}}-\mathrm{VI}^{\mathrm{e}}$ siècles: Priscus, Théophylacte Simocatta (ce dernier repris et quelquefois complété par le chroniqueur du IX ${ }^{\mathrm{e}}$ siècle, Théophane le Confesseur). Ces sources étaient connues depuis longtemps ${ }^{113}$ par les érudits roumains. Priscus, auteur d'un passionnant récit d'une ambassade de l'empereur d'Orient, Théodose II, auprès du roi des Huns, Attila 114, raconte qu'une petite cité romaine des bords du Danube, Asemos ou Asemus (act. Osãm Kalessi, près de Nikopol, en Bulgarie), fut capable de tailler des croupières à un fort parti de Huns, en 442, et de prendre l'initiative de négocier avec ces Barbares sans

111 Entre autres contributions, P. SKOK, "La terminologie chrétienne en slave: l'église, les prêtres et les fidèles", Revue des Études Slaves 7 (1927), p. 177-198; "Zum Balkanlatein”, Zeitschrift für romanische Philologie I: 46 (1926), p. 385-410, II: 48 (1928), p. 398-413, III: 50 (1930), p. 484-532, IV: 54 (1934), p. 175-215, V: ibid., p.424-499; "Byzance comme centre d'irradiation pour les mots latins des langues balkaniques", Byzantion 6 (1931), p.371-378.

112 Nous citerons les articles et ouvrages rédigés en français par celui qui fut à l'époque un des plus grands écrivains francophones: N. IORGA, "La Romania danubienne et les Barbares au VIe siècle", Revue belge d'histoire et de philologie 3 (1924), p. 35-56; "Le Danube d'Empire", in Mélanges offerts à M. Gustave Schlumberger à l'occasion du quatrevingtième anniversaire de sa naissance (17 octobre 1924), Paris, 1924, p. 12-22; "Les plus anciens États slavo-roumains sur la rive gauche du Danube (VII ${ }^{\mathrm{e}}$ siècle)", Revue des Études Slaves 5 (1925), p. 171-176; La place des Roumains dans l'Histoire universelle, Bucarest, 1935-1936, rééd. 1980, p. 63-79.

113 PRODAN, Supplex, p. 443: "... certum enim est ipso etiam saeculo VI plures ibidem Romanis in Oriente Imperatoribus, ad ripas praesertim Danubii, paruisse arces, interriores vero Provinciae partes tanto Romanorum incolarum numero abundabant, ut iam circa saeculum VII, excusso advenarum iugo, propriam exigerent Rempublicam.»

114 Récit d'autant plus vivant qu'il faisait lui-même partie de cette ambassade qui fit route de Constantinople au camp d'Attila durant l'été de l'année 449! Cf. dans les fragments de l' Histoire Gothique du rhéteur et sophiste Priscos, conservés par les soins de Constantin VII Porphyrogénète (Excerpta de legationibus Romanorum ad Gentes, éd. C. DE BOOR, Berlin, 1903, Excerpta e Prisco, 3, p. 122-148). 
l'aval de Constantinople ${ }^{115}$. Un siècle plus tard, Asemos se distingue en refusant de se soumettre au diktat du frère même de l'empereur Maurice et chef de l'armée romaine du Danube, Pierre, qui ordonnait au corps de troupe qui y tenait garnison d'être incorporé à ses forces ${ }^{116}$. Asemos n'est d'ailleurs pas la seule communauté urbaine sur les rives du Danube à montrer son autonomie. Novae (act. Svishtov en Bulgarie) oblige le même Pierre (qui décidément fait une campagne catastrophique en 595!) à assister à la célébration des fêtes en l'honneur du saint patron local, Lupus ${ }^{117}$. Dans le même temps, en toute première ligne face aux Avars et aux Slaves, la cité de Singidunum (act. Belgrade en Serbie) se conduit comme une véritable république militaire ${ }^{118}$.

Il a semblé donc à Iorga, suivi par Brãtianu, qu'aux Ve et VIe siècles, bénéficiant de l'éloignement de Constantinople et de la rupture des communications consécutives aux invasions barbares, un "pays latin» appuyé sur des cités bien fortifiées sur les bords du Danube a pu se maintenir, «envers et contre tous», à l'instar de Venise et des villes dalmates sur les côtes de la Mer Adriatique 119! «Ces villes [...] largement autonomes, avec leurs saints protecteurs, leurs évêques, leurs primats, leurs milices, leurs drapeaux» 120 ne seraient-elles pas le "chaînon manquant» entre l'ancienne Dacie romaine transdanubienne évacuée au temps d'Aurélien et les actuelles communautés roumaines du Banat, de Transylvanie, Valachie, Moldavie et Bucovine? Car l'influence latinisante de Bononia, Ratiaria, Oescus, Asemos, Durostorum, ne s'arrêtait bien évidemment pas à la rive gauche du Danube. Elle persistait dans l'arrière-pays, du Banat à la Valachie ${ }^{121}$.

Lorsque la ligne du Danube fut évacuée par les troupes de Byzance au début du VII e siècle sous la pression des Avars et des Slaves, le lien fut certes rompu entre les communautés proto-roumaines et le reste de la latinité européenne. Mais la solution de continuité fut, selon Iorga, la survie de populations de langue romane dans le cadre d' "États slavo-roumains" dont le plus important et le plus stable fut l'Empire, à l'origine touranien, des Bulgares. Au sud du Danube, la slavisation tout au long du Moyen Âge et de l'époque moderne ne fit que progresser, effaçant toute trace de langue romane. Mais, pour Iorga et aussi pour un historien roumain contemporain,

115 Excerpta de legationibus Gentium ad Romanos, p. 577-578. Cf. un commentaire sur cette affaire dans D. CLAUDE, Die byzantinische Stadt im 6. Jahrhundert, Munich, 1969, p.131.

116 Sur cet épisode (bien connu des historiens de Byzance), cf. Théophylacte Simocatta, Histoire de l'empereur Maurice, éd. C. DE BOOR, Leipzig, 1887, VII, 3, p. 249-251.

117 Théophylacte Simocatta VII, 2, p. 249.

118 Théophylacte Simocatta I, 4, p. 46; VI, 4, p. 226; VII, 10-11, p. 262-264.

119 IORGA, Place des Roumains, p. 68 et 71-72.

120 IORGA, "Le Danube d'Empire", p. 20.

121 N. IORGA "Les premières cristallisations d'état des Roumains", Bulletin de la Section Historique de l'Académie roumaine 5-8 (1920), p. 33-46; "La Romania danubienne", p.35-22. 
Nicolae Bãnescu ${ }^{122}$, l'élément "valaque» était encore aux XI ${ }^{\mathrm{e}}$ et XII ${ }^{\mathrm{e}}$ siècles assez puissant pour jouer le rôle principal en Bulgarie dans la résistance à la domination byzantine (rétablie au début du XI ${ }^{e}$ siècle par Basile II, rappelons-le) et dans la formation d'un second empire bulgare ${ }^{123}$.

Il est bien clair que si la latinité s'était conservée aussi vivace au sud du Danube en plein milieu du Moyen Âge, elle ne pouvait que permettre le maintien d'une forte communauté romane au nord de ce fleuve. Explication séduisante, mais inadmissible pour les historiens bulgares de l'époque! Il faut naturellement faire la part de la situation internationale. L'opinion publique bulgare sort traumatisée de la défaite de 1918 et des conséquences du traité de Neuilly (17novembre 1919), très défavorable pour la Bulgarie et très favorable pour la Roumanie ${ }^{124}$. Et puis le tableau dressé par les historiens roumains de Slaves bulgares apathiques menés à l'indépendance en 1185 par une classe dirigeante roumanophone ne pouvait que susciter les réactions les plus vives de la part des savants bulgares!

Très habilement, la contre-offensive bulgare va porter sur la définition à donner

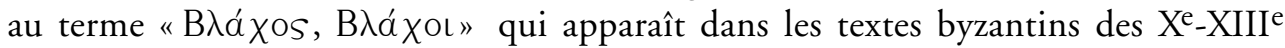
siècles. En effet, "Valaque» dans les Balkans modernes a un double sens. Il peut effectivement se rapporter à une population de langue romane, mais également désigner un genre de vie pastoral et montagnard ${ }^{125}$. Le grand historien bulgare, Vasil Zlatarski, a consacré une partie du second tome de sa vaste Histoire de l'Empire bulgare au Moyen Âge, paru en $1934^{126}$, à analyser les causes et circonstances du soulèvement «valaque» de 1185 contre Byzance à partir de la principale source, à savoir l'Histoire de Nicétas Choniatès ${ }^{127}$.

Selon Vasil Zlatarski qui s'appuie non seulement sur Nicétas Choniatès, mais aussi sur des sources occidentales (Ansbert, Villehardouin, Robert de Clari, correspondance du Pape Innocent III), «Valaque» est synonyme de «Barbare» habitant les hauteurs du Balkan situé dans l'ancienne Mésie devenue sous la deuxième domination byzantine le «thème du Paristrion». Et l'on voit bien ce que Zlatarski

122 Entre autres études, N. BÃNESCU, "Les premiers témoignages byzantins sur les Roumains du Bas-Danube”, Byzantinisch-Neugriechische Jabrbücher 3 (1922), p. $287-$ 311.

123 L'étude fondamentale sur cette question reste celle de WOLFF, «Second Bulgarian Empire».

124 LORY, "Bulgarie", p. 83.

125 Cf. supra, n. 43 et 44.

126 V. ZLATARSKI, Istorija na bälkarskata Dãrzava prez Srednite Vekove [Histoire de l'Empire bulgare au Moyen Âge], t. II: Bälgarija pod Vizantijsko Vladicestvo (1018-1187) [La Bulgarie sous la domination byzantine (1018-1187)], Sofia, 1934, 2e éd. 1972 (réimpr. et introd. D.A NGELOV). Le chapitre concernant le soulèvement des frères Asen, Pierre et Kalojan: Borba na osvobozdenie [La lutte pour l'indépendance], p. 410483; et sur la discussion sur le sens à donner au terme "valaque»: Etniceskijatã sãstavã na vãzstanieto [Le fondement ethnique du soulèvement], p. 416-419.

127 Sur l'Histoire de Nicétas Choniatès, cf. supra, n. 16. 
comprend par «barbare». Les frères «valaques», Pierre, Asen et Kalojan, sont en réalité des slaves bulgares habitant une région frontalière et montagnarde ayant toujours pratiqué un mode de vie pastoral et transhumant. Car il est invraisemblable de penser que la population romaine de la Dacie riveraine et de la Mésie II du temps de l'Antiquité tardive ait pu survivre aux invasions slaves et avares des VI ${ }^{\mathrm{e}}$-VII ${ }^{\mathrm{e}}$ siècles. Quand les Bulgares conduits par Asparuch s'installent en 679 dans ces provinces, ils n'y trouvent que des tribus slaves selon les rares sources écrites qui relatent l'événement ${ }^{128}$.

C'est donc bien la preuve qu'il n'y avait plus de «Romain» depuis longtemps dans ces contrées! L'historien bulgare Petãr Mutafciev résume la thèse bulgare en une phrase péremptoire et définitive, dans un ouvrage paru en français en 1932: «Pour un esprit non prévenu, il est clair qu'une population romane n'aurait pu vivre en Mésie après le VII ${ }^{\mathrm{e}}$ siècle sans laisser de trace. Si l'on ne parle pas de Roumains, c'est qu'il n'y en avait pas...! ${ }^{129}$ ». Sur la brèche ainsi ouverte par les Bulgares, s'infiltrent presque immédiatement les éternels «immigrationnistes» magyars. L'attaque la plus conséquente est portée, toujours en français, par Lajós Tamás ${ }^{130}$. L'historien hongrois reprend en fait, en l'actualisant, la thèse de la discontinuité, à une époque de particulière tension internationale. Le régime ultra-nationaliste de l'amiral Horthy fait de la question transylvaine son "cheval de bataille» au même moment.

Que Bulgares et Hongrois soient «immigrationnistes», il n'y avait là rien qui puisse surprendre les historiens roumains. Mais ils ne s'attendaient certainement pas à la prise de position d'un des plus grands spécialistes français du Haut Moyen Âge et des Grandes Invasions en la personne de Ferdinand Lot ! Celui-ci publiait en 1937 une étude sur la deuxième vague des Grandes Invasions, celle des VIe-VIIIe siècles,

128 Théophane le Confesseur, Chronographie, éd. C. DE BOOR, Leipzig, 1883, A.M. 6171, p.359, 13-14, qui mentionne les «sept tribus sklavènes» et les "Sévéries» destinés à slaviser plus tard leurs conquérants d'origine turque!

129 MUTAFCIEV, Bulgares et Roumains, p. 287; et aussi p. 142: "Jusqu'au moment où les Protobulgares fondèrent un État en 679, le reste de ces éléments romans a dû disparaître, absorbé par les Slaves de la Mésie». Le même historien exclut que des populations romanes aient pu subsister également sur la rive droite du Danube, dans les actuelles provinces de Valachie et de Dobroudja: Ibid., p. 308 et 358. Pourtant, des «esprits» aussi «non prévenus» que les géographes français Élisée Reclus et Emmanuel De Martonne avaient souligné en leur temps l'importance du peuplement roumanophone de part et d'autre de la vallée du Timok (régions de Zajecar, Negotin et Prahovo en Serbie, régions de Flortin, Vidin et Arcar en Bulgarie), mais aussi tout le long de la rive gauche du Danube. Cf. E.R ECLUS, Nouvelle Géographie Universelle, t. I: L’Europe méridionale, Paris, 1875, p. 224; E. DE MARTONNE, La Valachie. Essai de monographie géographique, Thèse, Paris, 1902, p. 236-244 (p. 243: "On peut considérer comme très vraisemblable que l'Olténie et le Banat ont conservé, même après la retraite des légions d'Aurélien, un certain nombre de colons romains, que le sang daco-romain y a été entretenu par le passage des pâtres dans la partie montagneuse, et que c'est là que s'est tout d'abord porté le courant d'immigration qui devait repeupler la Valachie et la Transylvanie»).

130 TAMÁS, Romains, Romans et Roumains, t. I, 1935, p. 1-96; t. II, p. 46-83. 
étude qui devait être une contribution à la compréhension des traités de paix de 1919$1923^{131}$. On a vu que l'heure était à la remise en cause de ces traités de paix par tout un courant révisionniste. Et voilà que l'illustre savant donnait raison aux thèses «immigrationnistes». Il considérait que la Dacie romaine avait été totalement évacuée par la population daco-romaine en 271 et qu'en aucun cas la Transylvanie n'avait pu servir de refuge à une population de langue romane ${ }^{132}$. Les deux grands arguments «discontinuistes» sont repris par Ferdinand Lot. Le premier est comme d'habitude l'argument ex silentio. À ce propos, l'auteur a ce jugement définitif: «...ce qui contrarie l'idée que, malgré tout, les Daco-Romains sont demeurés au moins partiellement en Dacie, c'est le silence des textes. Jamais, entre la fin du IVe et le XIII siècle, il n'est question d'une population romaine vivant dans l'ancienne Dacie. Ce mutisme de dix siècles est impressionnant.» ${ }^{133}$ Le deuxième était d'ordre linguistique: toponymie en Transylvanie entièrement d'origine hongroise ou slave, unité linguistique de l'ensemble daco-roumain et aroumain, liens entre les langues roumaine et albanaise ${ }^{134}$.

Quand les ancêtres des actuels Roumains ont-ils franchi le Danube pour peupler les terres de Transylvanie, Valachie et Moldavie? Ferdinand Lot pense que le mouvement a débuté au $\mathrm{X}^{\mathrm{e}}$ siècle. La Transylvanie fut la première des trois grandes provinces de la future Roumanie à être colonisée par les pasteurs «valaques». Puis la migration se porta au XIII ${ }^{\mathrm{e}}$ siècle vers le versant oriental des Carpathes, en Valachie et Moldavie ${ }^{135}$. La toponymie et la linguistique sont toujours mobilisées pour justifier aussi bien la chronologie des déplacements que l'itinéraire!

L'hypercriticisme de Ferdinand Lot de même que son pessimisme foncier à l'égard de l'Antiquité Tardive ${ }^{136}$ sont bien connus et suffisent largement à expliquer ses prises de position dans la controverse. Mais son honnêteté et son impartialité ne peuvent être suspectées. Ferdinand Lot prend bien soin de préciser que «...Nul peuple en Europe n'est installé de toute éternité sur le sol qu'il occupe actuellement. Les Roumains n'ont pas plus à céder la Transylvanie que les Anglais la Grande-Bretagne ou les Hongrois la vallée de la Theiss, pour retourner, les premiers en Allemagne, les seconds en Sibérie. Il faut peser les arguments en présence sans aucune considération

131 Sur le contexte des années 1935-1936, J.-B. DUROSELLE, Histoire diplomatique de 1919 à nos jours, Paris, Dalloz, 1971, p. 175-196.

132 LOT, Invasions barbares, p. 279-281.

133 LOT, Invasions barbares, p. 281-282.

134 LOT, Invasions barbares, p. 283; p. 285-286; p. 287.

135 LOT, Invasions barbares, p. 288-291.

136 Cf. le jugement très sévère de Henri-Irénée Marrou sur Ferdinand Lot: H.-I. MARROU, Décadence romaine ou Antiquité tardive? III -IV siècles, Paris, 1977, orientation bibliographique p. 181: «Le vieux manuel de F. Lot, La fin du monde antique et le début du Moyen Âge (Paris, Albin Michel, coll."L'évolution de l'humanité, 31", 1927), n'a de valable que son titre: on a rarement vu pareille incompréhension de son sujet par l'historien!» 
de politique contemporaine» ${ }^{137}$. Il était cependant difficile de nier que l'intervention de Ferdinand Lot dans la controverse constituait pour le camp des «immigrationnistes» un renfort d'autant plus appréciable qu'il venait d'un savant jugé tout à fait impartial.

Un véritable petit chef-d'œuvre de science historique, de prose française... et d'humour fut la réponse roumaine à l'étude de Ferdinand Lot, la même année. L'auteur, Gheorghe Brãtianu, est sans doute le plus brillant historien de l'école byzantiniste roumaine de ces années ${ }^{138}$. Un de ses ouvrages sert toujours de référence au problème des autonomies urbaines dans l'Empire byzantin ${ }^{139}$. Gheorghe Brătianu se sert donc de sa connaissance des choses de Byzance comme de celle des problèmes spécifiques du monde danubien pour répondre point par point à Ferdinand Lot qui est surtout un médiéviste «occidentaliste».

Le titre de l'étude de Brătianu donne un avant-goût du style employé par l'auteur: Une énigme et un miracle historique: le peuple roumain ${ }^{140}$, réplique quelque peu humoristique du titre du chapitre de l'ouvrage de Ferdinand Lot consacré aux origines roumaines! Gheorghe Brãtianu commence par présenter et résumer les études les plus récentes des partisans de la thèse "immigrationnistes», dont en premier celle de Ferdinand Lot, puis celles du bulgare Mutafciev, du hongrois Tamás et du «russe» (plus exactement bessarabien) Bromberg ${ }^{141}$. Très habilement, en rapprochant les diverses écoles nationales "immigrationnistes», en supposant qu'elles aient toutes raison, il démontre leur antinomie radicale. Les Hongrois refusent aux Roumains de revendiquer la Transylvanie comme leur foyer national, les Bulgares nient aux Roumains de s'être constitués en peuple sur le territoire des antiques Dacies subdanubiennes, les Russes ne veulent pas entendre parler d'une Bessarabie, berceau du peuple roumain! Et il s'avère impossible pour des raisons de bon sens de faire venir les Proto-Roumains des régions de l'actuelle Serbie. La situation serait cocasse, si elle n'était au fond tragique. Car on en arrive à la négation pure et simple du passé de tout un peuple ${ }^{142}$.

137 LOT, Invasions barbares, p. 283.

138 Réflexion que l'on jugera peut-être injustifiée! L'autre grand historien du moment, Nicolae Iorga, certes lui aussi byzantiniste confirmé, est surtout un «touche-à-tout» génial! Et parfois son imagination romantique l'a amené à des prises de position peu scientifiques!

139 G.I. BRÂTIANU, Privilèges et franchises municipales dans l'Empire byzantin, ParisBucarest, 1936.

140 Cf. supra, n. 94 et 102.

141 BRÃTIANU, Énigme, p. 9-36.

142 BRÃTIANU, Énigme, p. 34: «...la concordance de toutes ces opinions autorisées, qui nous obligent à chercher l'origine des Roumains du Moyen Âge partout, sauf en Roumanie, aboutit à cette conclusion paradoxale, mais évidente, que ce peuple qui n’a pas d'histoire, n'a pas non plus d'origine et de patrie. Ce serait vraiment à désespérer, si ce n'était risible.» Un peu plus haut, l'auteur pose la question existentielle par excellence: «Mais alors, d'où sont venus les Roumains? Serait-ce un cas de génération spontanée, à l'aube des temps modernes?» 
Et pourtant, les Roumains existent. Il faut donc bien qu'ils viennent de quelque part. Gheorghe Brătianu commence alors son travail de reconstitution, ou plutôt, devrait-on dire, de reconstruction du processus de l'ethnogénèse roumaine. Dans le troisième chapitre de son ouvrage, l'historien roumain reprend la question de l'évacuation de la Dacie au temps de l'empereur Aurélien et de la survie d'une communauté romane dans l'ancienne province romaine ${ }^{143}$. Comme beaucoup de ses prédécesseurs, il compare le cas de la Dacie avec celui d'autres régions frontalières romaines, Bretagne (l'actuelle Grande-Bretagne), «Alsace romaine» ${ }^{144}$, Norique (une partie de la Bavière et de l'Autriche actuelles) ${ }^{145}$. Ces derniers exemples démontrent qu'aucune évacuation ordonnée par les autorités romaines ne fut totale. Mais Brătianu sait aussi qu'en définitive la romanité disparut de ces anciennes régions frontalières romaines au bout d'une période plus ou moins longue ${ }^{146}$.

La seule solution réside dans le maintien de relations continues entre les deux rives du fleuve Danube. C'était déjà l'idée défendue dans les années 1880 par le roumain Dimitrie Onciul ${ }^{147}$. Le Danube ne fut jamais une frontière géographique, ethnique et culturelle étanche (sauf au temps des États nationaux - et nationalistes! de la fin du XIXe siècle et du XX $\mathrm{XX}^{\mathrm{e}}$ siècle), mais la voie de communication par excellence de l'Europe centrale et orientale ${ }^{148}$. Les échanges de populations, de marchandises et d'idées furent donc incessants entre les civitates et castella de la rive droite et les communautés villageoises de la rive gauche, du III ${ }^{\mathrm{e}}$ au VII ${ }^{\mathrm{e}}$ siècle.

Échanges de populations: Brãtianu considère que l'on peut considérer trois catégories de migrations «romaines» transdanubiennes, les «colons romanisés restés en Dacie», les "captifs entraînés au-delà du Danube par les conquérants germaniques, huns, avars ou slaves», "la population romanisée [...] des deux Dacies auréliennes, qui

143 BRÃTIANU, Énigme: "III. Les origines du peuple roumain: l'évacuation de la Dacie", p.36-61.

144 L. FORRER, L'Alsace romaine, Paris, 1935.

145 Les derniers temps du Norique romain et de son évacuation en 488 par les «Romains» sur ordre du "roi» Odoacre sont documentés de manière exceptionnelle par la Vie de Saint Séverin d'Eugippe (Eugippius, Vita Sancti Severini, éd. P. BECKER, [Aschendorffs Lesehefte zu Aschendorffs Sammlung lateinischer und griechischer Klassiker] Münster in Westfalen, 1955). Cf. également G. ALFÖLDI, Noricum, London-Boston, Routledge and Kegan Paul, 1974, p. 213-227.

146 Encore que le cas de la Britannia romaine présente des similitudes avec celui de la Dacie romaine en ce qui concerne la survie de communautés "romaines» (en Britannia, de communautés romano-celtiques en fait). Cette survie se réalise dans les zones qui étaient en quelque sorte extérieures à l'Empire: région des Carpathes après le III ${ }^{e}$ siècle, Cornouailles, Pays de Galles, Écosse et Irlande au Ve siècle (cf. S. FRERE, Britannia. A History of Roman Britain, London-Boston, Routledge and Kegan Paul, 1969, p. 423428).

147 Cf. supra, n. 75.

148 J. RITTER, Le Danube, Paris, P.U.F., coll. Que sais-je?, 1976; B. PIERRE, Le Roman du Danube, Paris, 1987. 
a dû repasser le Danube, pour fuir la double pression des Slaves qui s'installaient...» dans la péninsule balkanique ${ }^{149}$.

Échanges culturels: presque tout le vocabulaire religieux et ecclésiastique des Roumains provient des cités épiscopales de Dacie Riveraine et des deux Mésies tardoantiques ${ }^{150}$, ce qui nous amène au volet linguistique du dossier. Celui-ci est abordé dans le troisième chapitre de l'étude de Brătianu ${ }^{151}$. L'historien roumain utilise largement les travaux des principaux linguistes roumains du moment, Alexandru Rosetti et Sextile Puscariu. Selon ce dernier, approuvé par Brătianu, «la solution de la question des Roumains appartient à l'histoire» 152. C'est à l'historien de jouer le principal rôle dans la recherche des origines roumaines. Le linguiste n'intervient que pour "contrôler, et si possible... compléter... avec ses matériaux» 153. On peut saluer cette prise de position si on considère la place excessive prise dans la controverse par les philologues et linguistes.

Sur le plan linguistique, le fait le plus important est la remarquable unité du roumain, même en y incluant les ilôts balkaniques des Istroroumains, Macédoroumains et Méglénoroumains (cf. planche 2). Les "immigrationnistes» y voyaient la preuve d'une tardive séparation entre les principales composantes de la Roumanité, donc une formation récente et unitaire du roumain dans une zone géographiquement réduite de la péninsule balkanique proche du foyer primitif des Albanais ${ }^{154}$. Puscariu et Brãtianu expliquent l'origine de cette caractéristique linguistique du roumain tout à fait différemment.

À la base de l'albanais et du roumain, il y eut un seul et même substrat indigène «thrace, ou autre» ${ }^{155}$. En ce cas, il n'est plus nécessaire de rechercher une zone de contact entre Protoalbanais et Protoroumains! L'autre fait fondamental a été l'existence d'un latin danubien écrit et parlé dans l'Antiquité tardive, de la mer Noire à l'Adriatique et des Carpathes au centre des Balkans. Puis sous la pression des conquêtes et des invasions, cette zone romane s'est progressivement réduite comme une "peau de chagrin" aux régions romanes transdanubiennes. Seuls quelques ilôts appelés à dépérir ont subsisté au sud du Danube ${ }^{156}$. Dans ce processus, les cités latines du "Danube d'Empire» ont joué durant quelques siècles (III ${ }^{e}-\mathrm{VII}{ }^{\mathrm{e}}$ siècles) un rôle humain et culturel tout à fait fondamental. Mais il reste toujours ce fameux «trou noir» des sources entre la fin de la domination «romaine» sur les rives du Danube et

149 BRÃTIANU, Énigme, p. 57-58.

150 BRÃTIANU, Énigme, p. 69.

151 BRÃTIANU, Énigme: "IV. Les origines du peuple roumain: l'unité linguistique”, p. 6180.

152 S. PUSCARIU, Études de linguistique roumaine, Cluj-Bucarest, 1937, p. 110, cité dans BRÃTIANU, Énigme, p. 62-63.

153 BRÃTIANU, Énigme, p. 63.

154 LOT, Invasions barbares, p. 287.

155 BRÃTIANU, Énigme, p. 65.

156 BRÃTIANU, Énigme, p. 70-72. 
l'apparition des principautés roumaines de la fin du Moyen Âge à combler, «trou noir» qui permit à la thèse "immigrationniste» d'utiliser si souvent l'argument $e x$ silentio.

Le cinquième chapitre du livre de Brătianu est consacré à la discussion de cet argument ${ }^{157}$. Les textes byzantins et latins du Moyen Âge dont il a été fait état plus haut sont une fois de plus cités et analysés. L'interprétation de ces sources donne lieu à une hypothèse inédite et ingénieuse. Les Roumains des Balkans sont appelés Valaques à l'époque médiévale. Mais les Byzantins emploient aussi des termes venus de l'Antiquité, Mésiens, Scythes, qui s'appliquent à des peuples très divers, Goths, Huns, Petchenègues, Coumans, Tatars, etc. Brãtianu ne croit pas que cette habitude relève, comme on l'avance souvent, d'une mode archaïsante. Ces noms d'ethnies sont liés au territoire habité par celles-ci. Et c'est l'élément dirigeant, l'aristocratie conquérante gouvernant le territoire, qui impose son nom à l'ensemble de la population. C'est ainsi que les Roumains fréquentant les comptoirs génois de la mer Noire sont appelés dans les documents italiens "Hongrois», parce que sujets du roi de Hongrie aux XIII ${ }^{e}-\mathrm{XV}^{\mathrm{e}}$ siècles 158 .

"Valaque» ou Rumun prend souvent également une signification sociale dans les pays balkaniques et danubiens, celle de paysan attaché à la glèbe, celle de serf ${ }^{159}$. Il y a évidemment des exceptions: les Valaques Asénides des XII e et XIII e siècles constituent bien une ethnie "valaque» avec des couches sociales contrastées ${ }^{160}$. Mais c'est l'exception qui confirme la règle! Durant tout le Moyen Âge et une bonne partie des Temps Modernes, les "Valaques» ou Rumeni furent des asservis, des dominés. Le silence des textes s'explique par le fait que la littérature médiévale ne s'occupe pas de ces «laissés-pour-compte» des sociétés balkaniques et danubiennes ${ }^{161}$. La thèse était à la fois séduisante et romantique. Il se trouve que la dernière phase historique de la controverse allait s'orienter vers l'étude des "classes dominées et exploitées», avec l'installation de régimes communistes dans toute l'Europe du sud-est, après la fin de la Seconde guerre mondiale. Mais Gheorghe Brătianu ne devait pas survivre, comme tant de savants et d'intellectuels, à l'arrivée au pouvoir de Gheorghiu Dej en Roumanie ${ }^{162}$.

157 BRÃTIANU, Énigme: "V. Ethnographie et géographie", p. 80-101.

158 BRÃTIANU, Énigme, p. 84-85; il convient de rappeler que G. Brãtianu a commencé sa carrière de chercheur par l'étude des comptoirs génois de la mer Noire (G. BRÃTIANU, Recherches sur le commerce génois de la Mer Noire au XIII siècle, Paris, 1929).

159 BRÃTIANU, Énigme, p. 90-92.

160 BRÃTIANU, Énigme, p. 88-89.

161 BRÃTIANU, Éigme, p. 91-93.

162 Cf. supra, n. 96. 


\section{Conclusion}

Après la Seconde guerre Mondiale, ce fut le temps des régimes communistes, aussi bien en Roumanie qu'en Hongrie et en Bulgarie. On aurait pu croire que l'idéologie internationaliste de ces régimes aurait instauré une certaine modération dans les ardeurs nationalistes des camps en présence. Or, il n'en fut rien, surtout après la fin de l'époque stalinienne. Les écoles nationales roumaine, bulgare et hongroise continuèrent à s'affronter sur la question transylvaine, sur celle des Valaques Asénides. Mais, malgré tout, la science historique progressa, notamment au niveau de l'archéologie et de la linguistique, avec des savants comme les Bulgares Vladimir Georgiev, Veselin Besevliev, Velizar Velkov, Vasilka Tãpkova-Zaïmova, les Roumains Haralambie Mihãescu, Henri H. Stahl, les Hongrois Andreas Mócsy, Istvan Boná et bien d'autres.

En définitive, la période la plus critique pour la recherche historique est bien celle qui a suivi l'effondrement des régimes communistes dans les années 1990. Pauvreté et surexcitation des nationalismes ont été une catastrophe à la fois intellectuelle et matérielle.

Quel bilan peut-on alors dresser actuellement de deux cents ans de controverse? Est-ce, comme l'avance Lucian Boia, un "match nul» entre "continuistes» et "discontinuistes» 163? Il est effectivement difficile de départager les deux camps. Mais on peut penser que la controverse fut durant deux siècles une passionnante école de recherche pour les historiens de toute l'Europe!

Michel PILLON

Centre Universitaire Jean-François Champollion, Albi

5, Cité Saint Michel

F-81380 Lescure d'Albigeois

pillon.nelly@tiscali.fr

163 Cf. BOIA, Roumanie, p. 65. 